\title{
دراسة تحليلية لسلسلة القيمة لمحصول البطاطس بمحافظة المنوفية
}

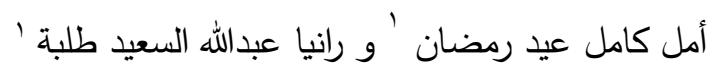

الإنتاج والتي تتمثل في توفير مستلزمات الإنتاج للمحصول.

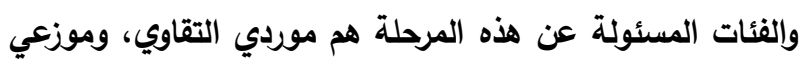

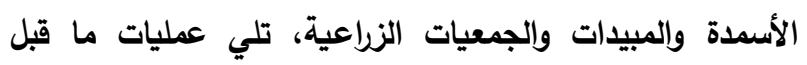

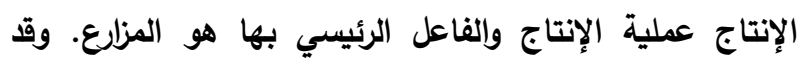

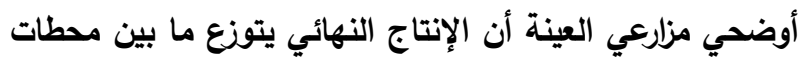

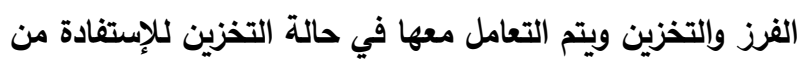

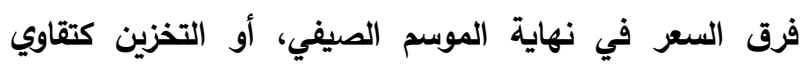

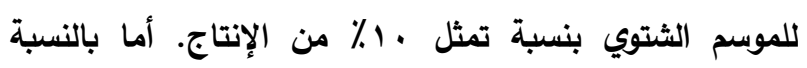

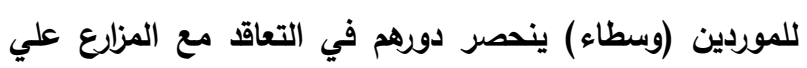

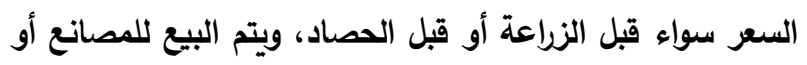

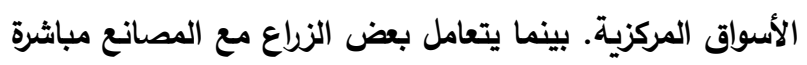

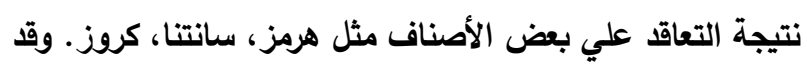

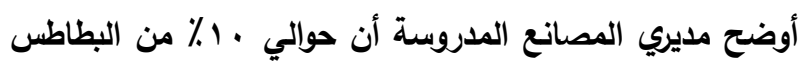

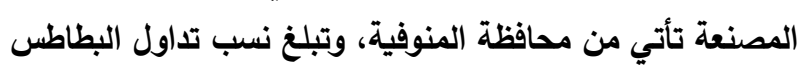

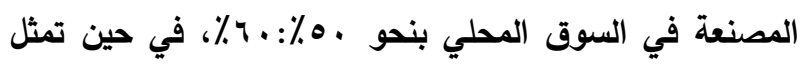

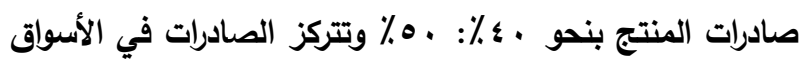

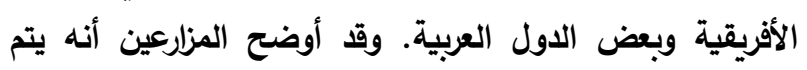
التعامل مع تجار الجملة نظير توفير التقاوي والاسمدة بالآجل.

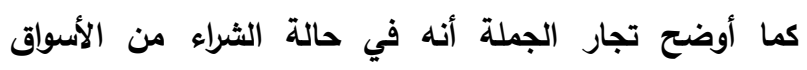

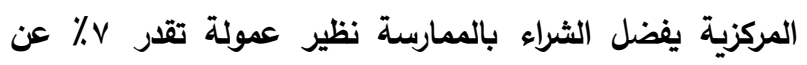

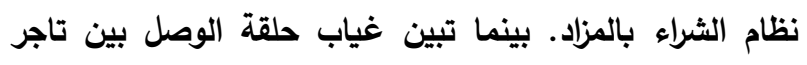

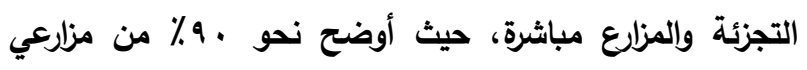

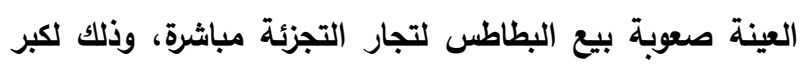

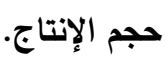

وبدراسة القيمة المضافة للبطاطس تبين أنها توفر فرص الإنتاج

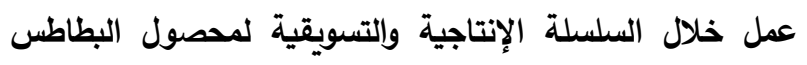

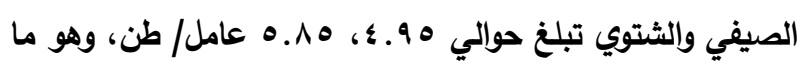

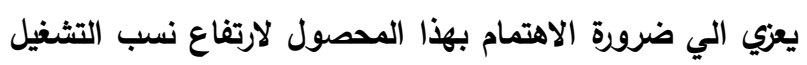
به. وبدراسة القيمة النقدية المضافة للطن المنتج يتبين أن أرباح

\section{الملخص العربى}

يعتبر تطوير سلاسل القيمة للمحاصيل الزراعية، من أهم

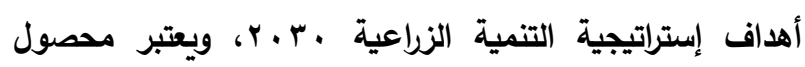

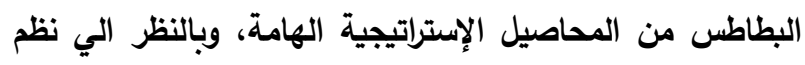
تداول البطاطس يتبين غياب التنسيق بين الأطراف المتعاملة

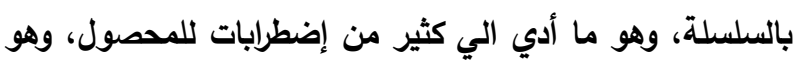

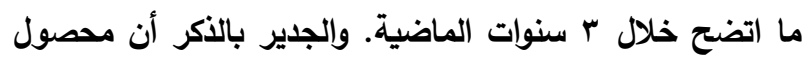
البطاطس يمثل نحو ^^ء ٪ من مساحة الخضر بمحافظة المنوفية.

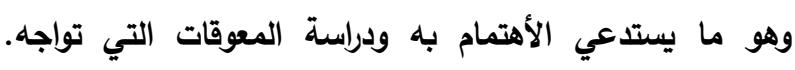
ويتبلور الهلف الرئيسي إلى تحليل سلسلة القيمة للبطاطس

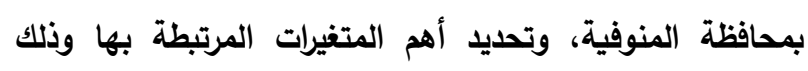

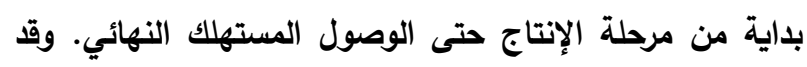

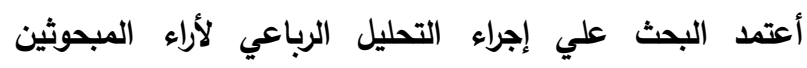

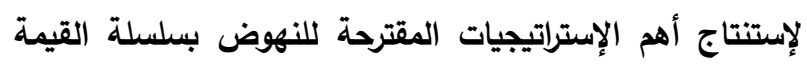
لمحصول البطاطس بالمنوفية. وكانت من أهم النتائج البحثية

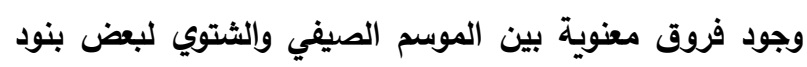

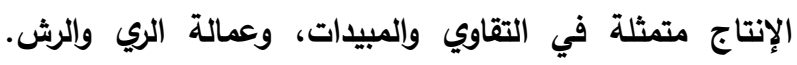

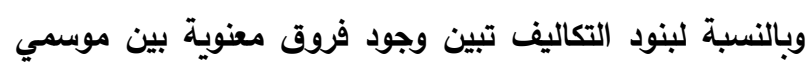
الززاعة لكل من التكاليف الكلية والتكاليف المتغيرة. هذا وقد تبين

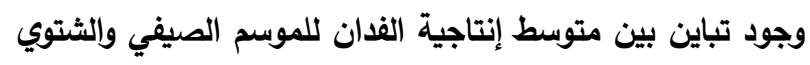

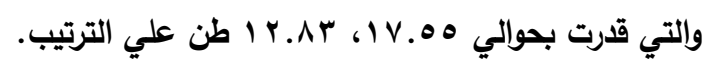

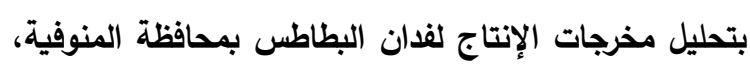

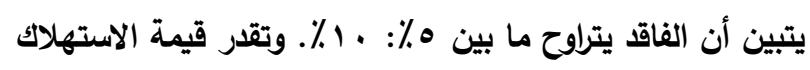

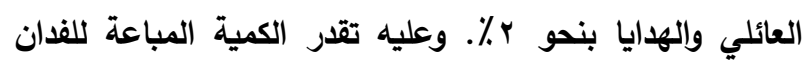

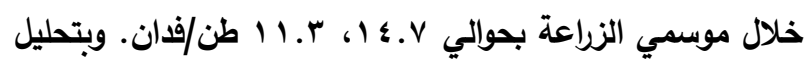

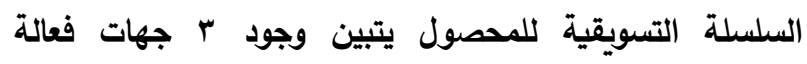
للتعامل، كما تبين عدم وجود نظم لربط المزارعين بالاسواق.

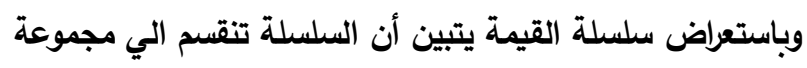

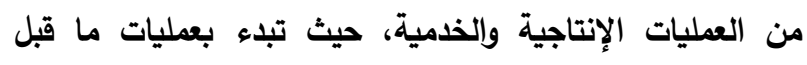

'باحث أول معهة بحوث الاقتصاد الزراعي- مركز البحوث الزراعية

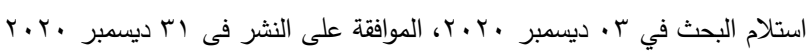




\section{المقدمة}

يعتبر تطوير سلاسل القيمة للمحاصيل الزراعية، من أهم

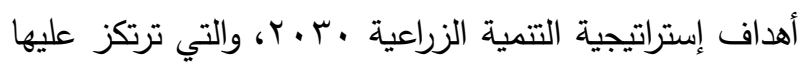
معظم مبادئ وسياسات الإستراتيجية، حيث أنها لاتهدف فقط

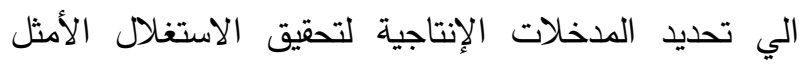

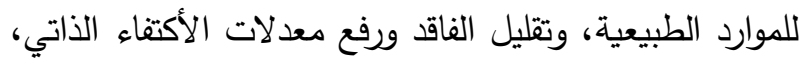
ودفع عجلة التتمية الريفية. الإ أنها تهاف الي تحليل أوجه

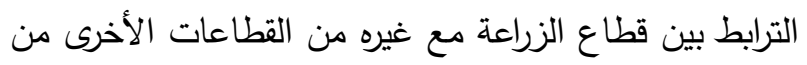
الاقتصاد الوطني كالنقل والتجارة والصناعة. ويركز مفهوم سلسلة القيمة على المزايا التنافسية ومعرفة عناصر القوة والضعف. من خلال تحليل سلسلة الأنثطة الرامية إلى الى الثرفي تحويل المدخلات إلى مخرجات والتي تتطلب أنثطة أساسية أو داعمة. ولقد عرف بورتر 1910 سلسلة القيمة بأنها الخطوات المتعاقبة في عملية الإنتاج أو الأنشطة التي تضيف القيمة إلى المنتج حتى يصل إلى المستهلك النهائي وهي تعتمد على القيمة المضافة في كل مرحلة من المراحل. ولتعزيز سلسلة القيمة لابد من توضيح الأطراف المتثاركة

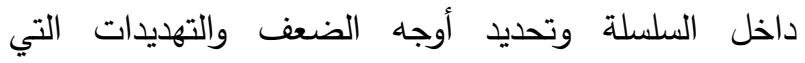
تواجهه، بالإضافة الي تعزيز نقاط القوة والفرص المتاحة

ومما لا شك أن مصر تتمتع بمقومات طبيعية لإنتاج محاصيل الخضر مما يجعل لها ميزة نسبية وتنافسية في الأسواق العالمية، الإ أن تعدد الجهات المشاركة في السلسلة

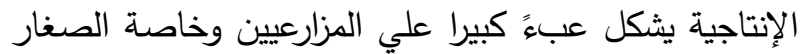

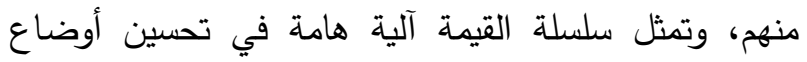
صغار المزراعين، وتساعدهم في ربط منتجاتهم بالأسواق. ويعتبر محصول البطاطس من أهم محاصيل الخضر، حيث يأتي في المرتبة الثانية من حيث المساحة المزروعة

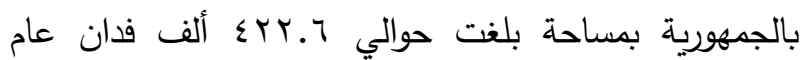

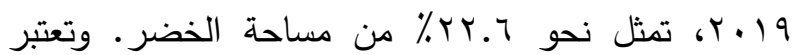

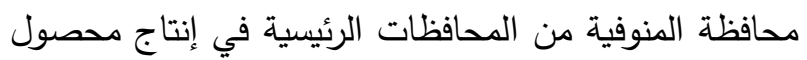
البطاطس بالوجة البحري، حيث تبلغ المساحة المزروعة
الوسطاء تفوق أرباح المنتجين، وعليه فإن تفعيل دور الززاعات

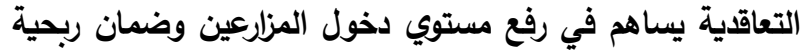
عادلة للمزارع وذلك وفق عقود ملزمة لكل الأطراف. وبإجراء التحليل الرباعي لسلسة القيمة للبطاطس بمحافظة المنوفية يتبين أن نقاط القوة تتمثل في سرعة دولان رأس المال، توافر الخبرة في الززاعة وتوفير فرص عمل، وأن محصول فئن البطاطس محصول إستراتيجي وقومي. في حين تتمثل نقاط الضعف في ارتفاع أسعار مستلزمات الإنتاج، أرتفاع نسب فئن

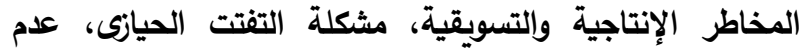
وجود روابط للمنتجين، أرتفاع نسب الفاقد والتالف. وتأتي التهايدات كأحد العوامل الخارجية المؤثرة علي المنتج وتتمثل في ضعف الدور الإرشادي والتعاوني، زيادة عداد الوسطاء، ضعف كفاءة البنية التحتيه، تداول تقاوي ومبيدات وأسمدة مغشوشة، عدم وجود عقود ملزمة بين المزارعين

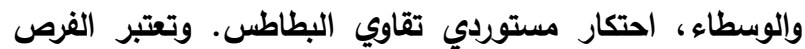
المتاحة أهم داعم للمحصول فيتبر تفعيل دور المؤسسات

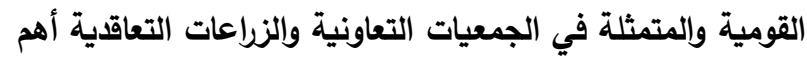
المتغيرات تاثيراً علي المحصول، يليها في التاثير كل من إمكانية إنثاء مراكز تجميع للحاصلات الزراعية، التوسع فى التصنيع الززاعي، تبني الدولة لإستباط أصناف محلية، إتجاه الدولة التئ

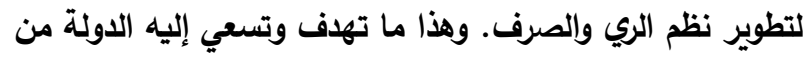

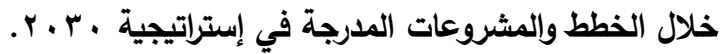
ومن واقع تحليل سلسلة القيمة لدحصول البطاطس وفق أراء مبحوثي العينة، تم تحديد أهم الإستراتيجيات المتبعة للنهوض الفيلة بسلسلة إنتاج وتداول البطاطس بمحافظة المنوفية. وأهمها تطبيق إستراتيجية نمو وتوسع تليها إستراتيجية التطوير

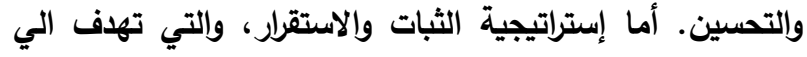
الإستغلال الأمثل للموارد وتقليل الهار بمواجهة التهايدات وفق التقات

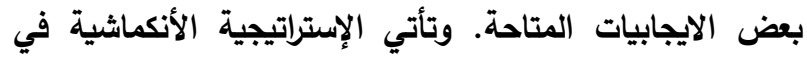
حالة تربي الأوضاع وذلك بزيادة مستويات الضعف والتهايدات، وتعتمد هذه الإستراتيجية علي علاج مشكلة مستلزمات الإنتاج والمتمثلة في المقام الأول مشكلة التقاوي. الكلمات المفتاحية: سلسلة القيمة- نموذج التحليل الرباعي )-(SWOT) 
أمل كامل عيد رمضان و رانيا عبدالله السعيد طلبة: دراسة تحليلية لسلسلة القيمة لمحصول البطاطس بمحافظة المنوفية 637

ء. تحديد أهم الإستراتيجيات المتبعة للنهوض بسلسلة إنتاج

وتداول البطاطس.

الأسلوب البحثي ومصادر البيانات:

في ضوء أهداف البحث تم استخدم كل من الأسلوب

التحليلي الوصفي والكمي عند تقدير المتغيرات موضع هوة الدراسة، كالمتوسطات والنسب المئوية وتحليل التباين وذلك لتحليل بنود مدخلات الإنتاج والتكاليف بعينة الدراسة، بالإضافة الي تحليل المسلك التسويقي وتحديد الجهات الفعالة به، وتقدير القيمة المضافة للعمل ورأس المال علي طول السلسلة. هذا بالإضافة الي إجراء التحليل الرباعي (SWOT) وفق لاراء المبحوثين لإستتتاج أهم الإستراتيجيات المقترحة للنهوض بسلسلة القيمة لمحصول البطاطس بالمنوفية. وقد إعتمد البحث في بياناته على مصدرين أساسيين، الأول البيانات المنشورة من كل من وزارة الزراعة واستصلاح

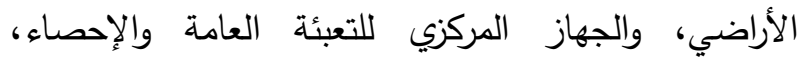
والمصدر الثاني البيانات الميدانية تم تتفيذها على مستويات مختلفة متمثلة في المزارعين وتجار الجملة وتجار التجزئة

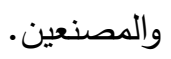

\section{النتائج ومناقشتها}

1. الأهمية النسبية لإنتاج البطاطس بعرواته وتطور الطاقة الإنتاجية للبطاطس ب ج.م.ع ومحافظة المنوفية: يعتبر محصول البطاطس من محاصيل الخضر الرئيسية فى مصر حيث يزرع على ثلاث عروات صيفي ونيلي وشتوي. تحتل العروة الصيفي للبطاطس فى مصر مكانه هامة لدى جميع مزارعى البطاطس حيث أنها تعتبر المصدر

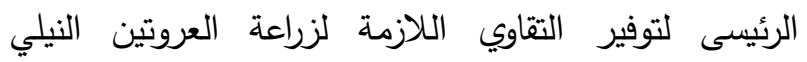

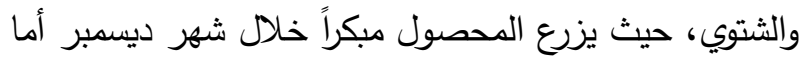
معظم مساحات هذه العروة فتزرع خلال شهر يناير وحتى

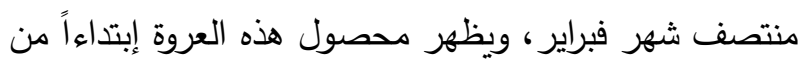
أوائل شهر أبريل وحتى منتصف شهر يونيو، بينما العروة الثتوي هي العروة الرئيسية لإنتاج البطاطس فى مصر حيث

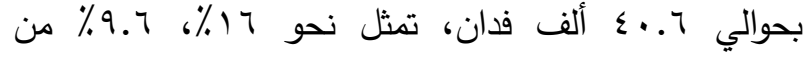
اجمالي مساحة البطاطس بالوجه البحري والجمهورية علي

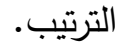

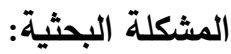

تُعد البطاطس مصدر رئيسي للدخل خاصة بالنسبة لصغار المزارعين، حيث تتميز بصغر دورة حياتها، ثبات الإنتاجية، تعدد العروات، زيادة الطلب عليها نظراً لانها مصدر غذائي لكثير من الأسر منخفضة الدخل. وعلي الرغم من هذا الإ أن محصول البطاطس في الارضي القديمة وخاصة محافظة المنوفية يواجه كثير من التحديات أهمهاغياب التتسيق بين الأطراف المتعاملة بالسلسلة، وهو ما ما مانه أدي الي كثير من الفقد والهدر في الموارد الزراعية بالإضافة الي اضطرابات في الأسعار وذلك لضعف المعلومات التسويقية، وهو ما أتضح خلال ب سنوات الماضية من الن اضطرابات سعر البطاطس خاصة بين فترات تعاقب المحصول. والجدير بالذكر أن محصول البطاطس يمثل نحو ^§ \% من مساحة الخضر بمحافظة المنوفية خلال العام

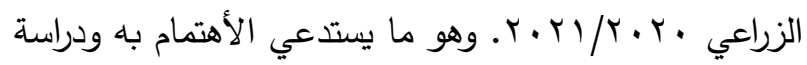

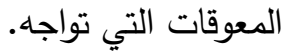

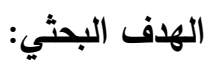

يتبلور الهدف الرئيسي إلى تحليل سلسلة القيمة للبطاطس بمحافظة المنوفية، وتحديد أهم المتغيرات المرتبطة بها بداية من مرحلة الإنتاج حتى المستهلك النهائي، وذلك من خلال

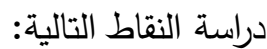
1. الأهمية النسبية لإنتاج البطاطس بعرواته وتطور الطاقة الإنتاجية للبطاطس ب ج.م.ع ومحافظة المنوفية. r. تحليل سلسلة القيمة لمحصول البطاطس بمحافظة

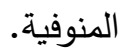

r. التحليل الرباعي لسلسة القيمة لمحصول البطاطس بمحافظة المنوفية. 
المساحة المنزرعة بالمحصول علي مستوي الجمهورية بلغت

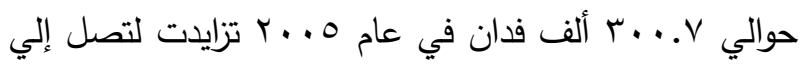

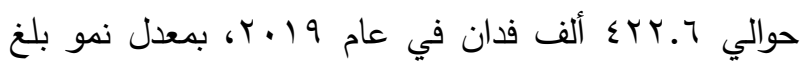
نحو ؟.r\% سنوياً، وفيما يتعلق بالإنتاجية الفدانية تبين أنها

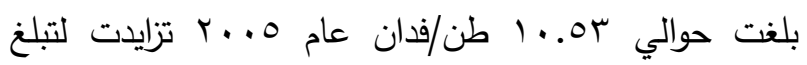

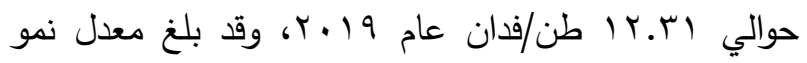
الإنتاجية و.٪ سنوياً. في حين بلغ الإنتاج الكلي

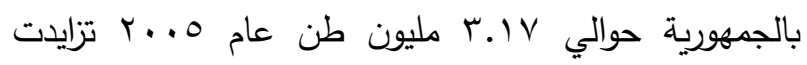

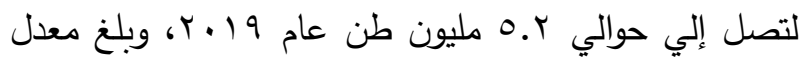
النمو r.ء \% سنوياً.

أما فيما يتعلق بمحافظة المنوفية أتضح أن المساحة

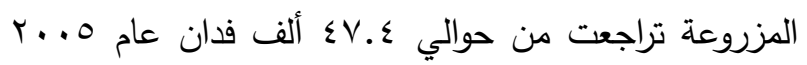

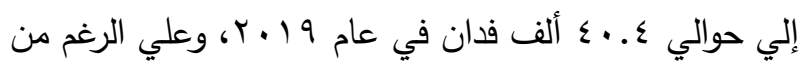

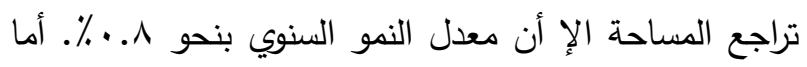
بالنسبة للإنتاجية الفدانية فتزايدت من حوالي 9.0 طن/فدان إندان

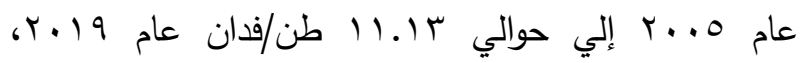
بمعدل نمو بلغ r. • ٪ سنوياً، وبالرغم من انخفاض المساحة الي أن الإنتاج يتميز بالاستقرار خلال بداية ونهاية السلسلة الزمنية ويرجع ذلك لزيادة الإنتاجية، حيث بلغ الإنتاج الكلي

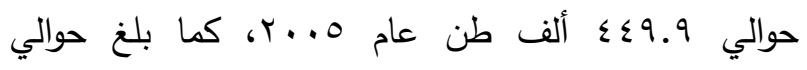

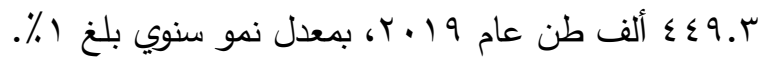
r. تحليل سلسلة القيمة لمحصول البطاطس بمحافظة

المنوفية.

تبدأ سلسلة القيمة للبطاطس بتوفير مستلزمات الإنتاج،

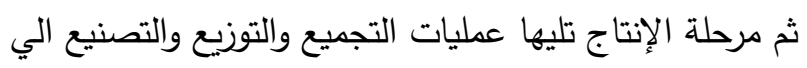
أن تصل الي المستهلك النهائي. ولابد من الأخذ في الإعتبار أن محصول البطاطس بالاراضي القديمة يتم تداوله علي

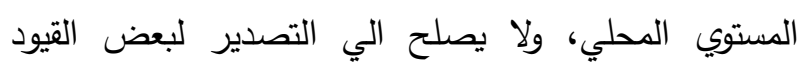
والاثتراطات الصحية المتعارف عليها دولياً.

وبدراسة السلسلة يتضح وجود جهات فعالة في كل مرحلة، تواجه كل جهة بعض القيود والمحددات، كما تتمتع
تُزرع خلال منتصف أغسطس وحتى نهاية شهر أكتوبر ويستخدم فى زراعتها التقاوى المحلية السابق حجزها من محصول العروة الصيفية السابقة لها بعد تخزينها خلال أشهر الصيف فى الثلاجات أو النوالات المنتشرة فى بعض بعله محافظات مصر، ويظهر إنتاج هذه العروة إعتباراً من منتصف شهر ديسمبر حتى منتصف شهر فبراير، ويأتي زراعة العروة النيلي من منتصف شهر أكتوبر وحتى منتصف دهفي شهر نوفمبر وتستخدم فى زراعة هذه العروة تقاوى معتمدة محلياً ناتج العروة الصيفية السابقة ويظهر إنتاج هذه العروة من أواخر فبراير إلي أواخر مارس وهي عروة مساحتها

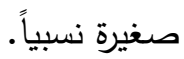
يتبين من بيانات الجدول (1) الأهمية النسبية لإنتاج محصول البطاطس علي مستوي إجمالي العروات لجمهورية مصر العربية ومحافظة المنوفية خلال متوسط الفترة

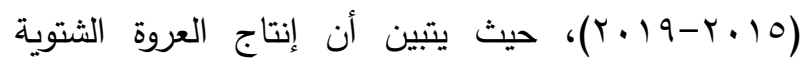
بالجمهورية يمثل أكبر نسبة من إجمالي إنتاج العروات

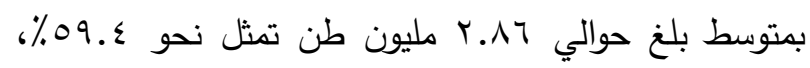

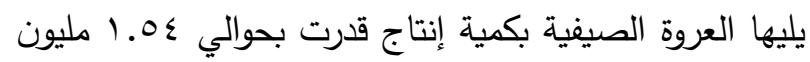

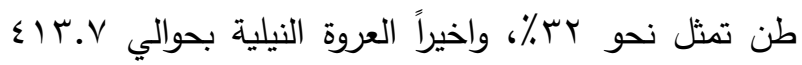
ألف طن تمثل نحو 1. ٪\% من متوسط إجمالي إنتاج

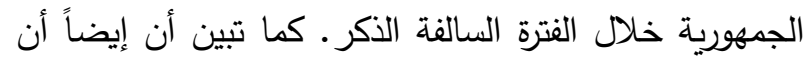
إنتاج العروة الثتوي بمحافظة المنوفية يمثل أكبر نسبة من إجمالي إنتاج عروات البطاطس بمتوسط بلغ حوالي ب.7.7 ألف طن تمثل نحو 0.0\%، يليها العروة الصيفية بكمية إنتاج قدرت بحوالي ابr ألف طن تمثل نحو 9 ؟٪، واخيراً

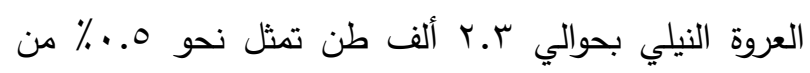
متوسط إجمالي إنتاج محافظة المنوفية. وبدراسة تطور الطاقة الإنتاجية بعنصريها المساحة

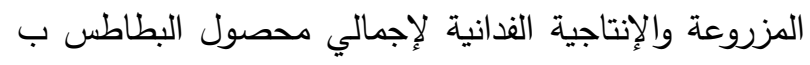

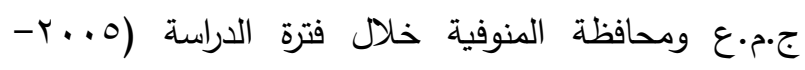

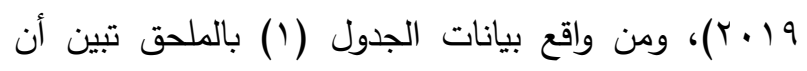


أمل كامل عيد رمضان و رانيا عبدالله السعيد طلبة: دراسة تحليلية لسلسلة القيمة لمحصول البطاطس بمحافظة المنوفية 639

وقد أعقب ذلك اختيار أكبر قريتين من كل مركز بحيث تمثل أكبر مساحة، ووفقا للجدول رقم (r) تم اختيار قرية سرس الليان، فيشا كبري من مركز منوف خلال موسمي الزراعة، بينما تم اختيار قرية البندارية، كفر ربيع بمركز تلا

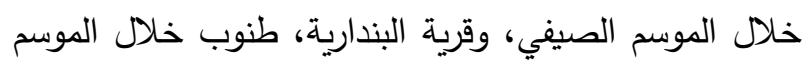
الثتوي. وبالنسبة لمركز أشمون تم اختيار قرية البرانية، سبك الأحد للموسم الصيفي، وقرية طليا، البرانية للموسم الثتوي

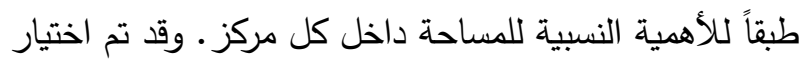
عينة عشوائية بسيطة من واقع سجلات الجمعيات الزراعية

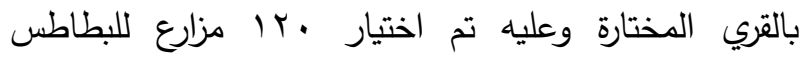

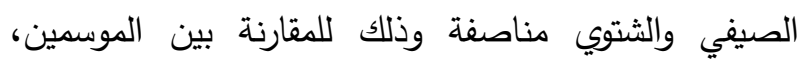
وتحقيقا لهدف الدراسة تم أختيار ـا مفردة من كل قرية.
ببعض المككنات والفرص. وعليه تم إجراء استيان لممثلي بعض الجهات لاستطلاع آرائهم. أ. وصف عينة الدراسة: وفقاً التركيب الإداري لدحافظة المنوفية فأنها تتكون من 9 مراكز، وبمراجعة البيانات الإحصائية بمديرية الزراعة

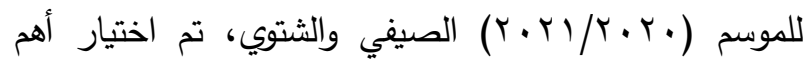
ثلاث مراكز لإجراء الدراسة بها وهما منوف، تلا، أشمون،

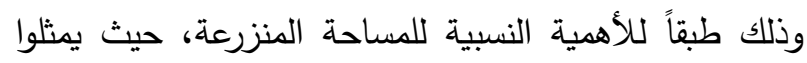

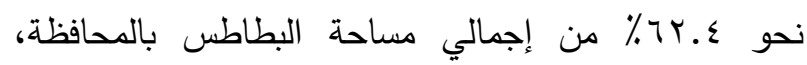
وتمثل مساحة البطاطس الصيفي نحو ع.ءه٪، ومساحة البطاطس الثتوي نحو 19.0\% كما بالجدول (r). وقد تم استبعاد العروة النيلي حيث أنها لا تمثل مساحة تذكر.

جدول 1.الأهمية النسبية لإنتاج البطاطس علي مستوي إجمالي العروات لجمهورية مصر العربية ومحافظة المنوفية خلال

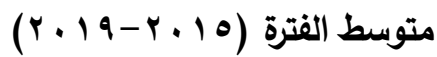

\begin{tabular}{|c|c|c|c|c|}
\hline \multicolumn{2}{|c|}{ محافظة المنوفية } & \multicolumn{2}{|c|}{ الجمهورية } & البيارا \\
\hline الأهمية النسبية \% & الإنتاج بالألف طن & آلأهمية النسبية \% & الإنتاج بالألف طن & 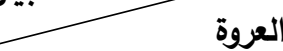 \\
\hline 0.0 & YYY.T & $09 . \xi$ & rAT..T & ل العروة الثتوى \\
\hline$\varepsilon 9 .$. & rr... & r... & 1049.1 & العروة الصيفي \\
\hline. .0 & r.r & 0.7 & $\varepsilon \mid r, \uparrow$ & العروة النيلي \\
\hline $1 \ldots$ & $\leqslant 0 \ldots 9$ & $1 \ldots$ & $\leq \wedge 1 \leqslant .$. & إجمالى العروات \\
\hline
\end{tabular}

المصدر: جمعت وحسبت من بيانات وزارة الزراعة، قطاع الثئون الإقتصادية، نشرات الإحصاءات الزراعية، أعداد مختلفة.

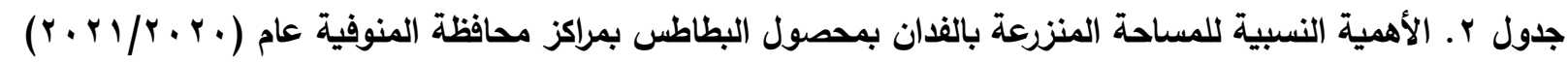

\begin{tabular}{|c|c|c|c|c|c|c|}
\hline \multirow{2}{*}{ 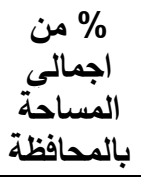 } & \multirow[b]{2}{*}{ المنساحة المنّي } & \multicolumn{2}{|c|}{ شتوي } & \multicolumn{2}{|c|}{ صيفي } & \multirow[b]{2}{*}{ المركز } \\
\hline & & \%المناحة اجمالح & المزالبطاحة المسة & \% بالمساحة اجمالحة & المسالبطاطرة المسرة & \\
\hline YT.E & I. ArN & Yร.ร & 0907 & YY.r & $\varepsilon \wedge \wedge r$ & منوف \\
\hline TY.T & 1.477 & I. & OTYV & rI. & $\varepsilon 7 r q$ & تلا \\
\hline 17.1 & $V \vee \leq \wedge$ & r... & orv & $1 \cdot .9$ & TrVE & أشمون \\
\hline $1 \pi .0$ & $T r \leqslant Y$ & $1 \cdot .7$ & ro90 & 17.8 & $r า \leqslant V$ & الشهداء \\
\hline $0 . V$ & rqrq & $9 .$. & Y) 10 & Y.I & $\leqslant 0 \leqslant$ & الباجور \\
\hline 0.7 & rOA & $1 . \varepsilon$ & qu & $1 . r$ & $r r \leq r$ & بركة السبع \\
\hline$\varepsilon . r$ & $19 r 1$ & r.9 & Vil & 0.7 & $M I V$ & قويسنا \\
\hline Y. $\varepsilon$ & 111. & .7 & $1 \leqslant V$ & $\varepsilon . \varepsilon$ & & السادات \\
\hline r.. & 940 & $1 . \varepsilon$ & $r \varepsilon \varepsilon$ & T.V & $0 \wedge 1$ & شبين الكوم \\
\hline$\varepsilon . Y$ & $19 \leq V$ & $\varepsilon .0$ & $1.9 V$ & $r .9$ & No. & الاصلاح الزراعي \\
\hline $1 \cdots$ & $\varepsilon Y Y Y O$ & $1 \cdots$ & $r \leq r \vee v 0$ & $1 \ldots$ & Y $\wedge 0$. & الاجمالى \\
\hline
\end{tabular}




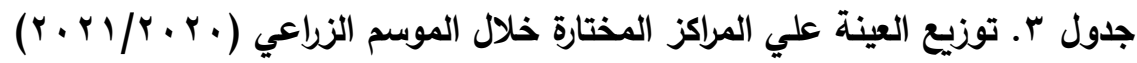

\begin{tabular}{|c|c|c|c|c|c|c|}
\hline \multicolumn{2}{|c|}{ شتوي } & \multirow{2}{*}{ القرية } & \multicolumn{2}{|c|}{ صيفي } & \multirow{2}{*}{ القرية } & \multirow{2}{*}{ المركز } \\
\hline \% من المركز & المساحة & & \% من المركز & المساحة & & \\
\hline 1 & $0 \wedge \Lambda$ & سرس الليان & 11 & $\wedge \vee \varepsilon$ & سرس الليان & \multirow{2}{*}{ منوف } \\
\hline 1. & 071 & فيشا الكبري & 11 & Ort & فيشا الكبري & \\
\hline $1 \ldots$ & 0907 & اجمالى المركز & $1 \ldots$ & $\sum \wedge \wedge r$ & \multicolumn{2}{|c|}{ اجمالى المركز ل } \\
\hline 11 & $7 \varepsilon$ & البندارية & 19 & $91 \mathrm{r}$ & البندارية & \multirow{2}{*}{ تلا } \\
\hline 14 & Vro & طنوب & 17 & VYO & كفر ربيع & \\
\hline $1 \ldots$ & OTYV & اجمالى المركز & $1 \ldots$ & $\leq 749$ & \multicolumn{2}{|c|}{ اجمالى المركز } \\
\hline$r r^{2}$ & 1171 & طليا & 11 & $\varepsilon r q$ & البرانية & \multirow{3}{*}{ أشمون } \\
\hline ir & $\pi r$. & البرانية & 14 & $r \cdot \varepsilon$ & سبك الأحد & \\
\hline $1 \ldots$ & orvE & اجمالى المركز & $1 \ldots$ & TrVE & اجمالى المركز الم & \\
\hline & & قري مركز أشمون & & ت تلا rع قر & & 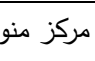 \\
\hline
\end{tabular}

من حوالي 9 ألف طن تقاوي بقيمة تقدر بحوالي 117

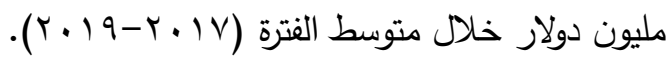
ووفق تقديرات بيانات العينة تبين أن متوسط إحتياجات الفدان من التقاوي خلال الموسم الصيفي والثتوي بعينة

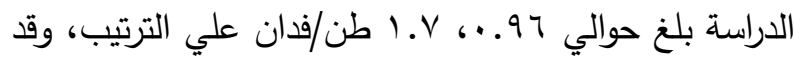
أوضح نتائج تحليل التباين وجود فروق معنوية في كمية التقاوي المستخدمة بين موسمي الزراعة. ويرجع سبب وجودي الأختلاف الي أن تقاوي البطاطس في الموسم الثتوي هي كسر للموسم الصيفي وعليه يتم إستخدام كميات مضاعفة من الصن التقاوي مقارنة بالموسم الصيفي. وقد قدر متوسط أقصي كمية للتقاوي بقرية فيثا الكبري بمركز منوف خلال الموسم

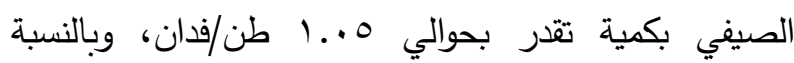
للموسم الثتوي قدر أقصي كمية تقاوي بقرية طنوب بمركز

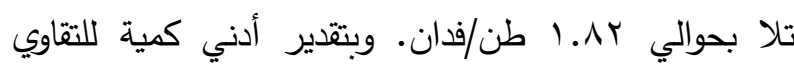
خلال موسم الزراعة الصيفي تبين أن قرية البندارية بمركز

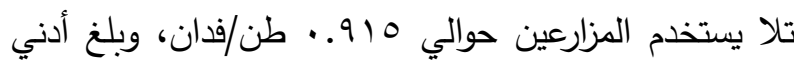
كمية تقاوي للموسم الثتوي بقرية طليا بمركز أشمون بكمية

$$
\text { بلغت حوالي به ـ ا طن/فدان. }
$$

r) الأسمدة العضوية والكيماوية: أوضحت بيانات العينة أن

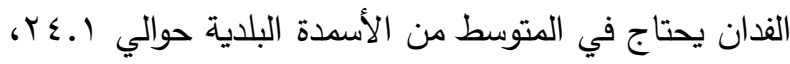
r.ـا مץ خلال الموسم الصيفي والثتوي علي الترتيب.
في حين تم اختيار عينة عمدية للفئات الآخري

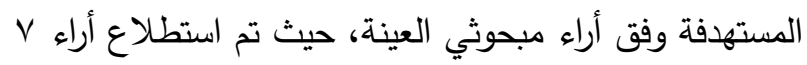
من موردي مستلزمات الإنتاج، ب من مديري محطات

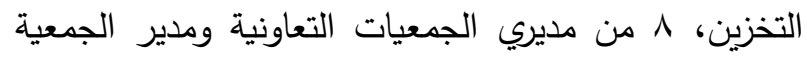
التعاونية العامة لمنتجي البطاطس، 9 من تاجري الجملة والتجزئة، بالإضافة إلي r من مديري مصانع البطاطس، وذلك بهدف تتبع السلسلة بداية من المنتج وحتى وصول

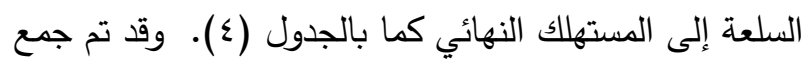
بيانات الدراسة عن طريق المقابلة الثخصية للمبحوثين بواسطة استمارة استبيان أعدت خصيصا لكل جهة. هذا عرئ بالإضافة الي المجموعات النقاشية لممثلي الجمعيات التعاونية.

ب.تحليل مدخلات الإنتاج لفدان البطاطس بمحافظة المنوفية

بإستعراض البيانات الواردة بالجدول (0) والتي توضح

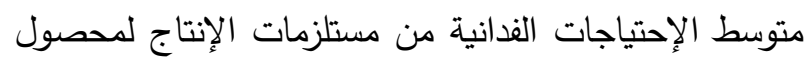
البطاطس بمحافظة المنوفية خلال موسمي الزراعة، يتضح ما يلي: () التقاوي: تواجه تقاوي البطاطس مشاكل عدة خاصة

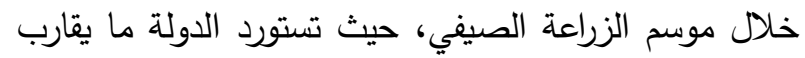


أمل كامل عيد رمضان و رانيا عبدالله السعيد طلبة: دراسة تحليلية لسلسلة القيمة لمحصول البطاطس بمحافظة المنوفية 641

جدول ع. الجهات الفعالة بسلسلة القيمة لمحصول البطاطس بمحافظة المنوفية المستطلع آرائهم للموسم الزراعي

\begin{tabular}{|c|c|c|c|c|c|c|c|}
\hline مصنعين & تجار تجزئة & تجار جملة & تعمعيات & محطات فرز & موردي مستلزمات & مزارعين & الجهه \\
\hline$r$ & $\varepsilon$ & 0 & $\wedge$ & $r$ & $V$ & $1 \%$ & العدد \\
\hline
\end{tabular}

إستخدام العمل البشري لعملية الري خلال موسمي الزراعة

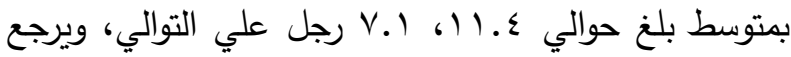
ذلك لإختلاف عدد الريات خلال موسمي الزراعة، حيث بلغ متوسط عدد الريات للموسم الصيفي بحوالي لا رية، بينما بلغ خلال الموسم الثتوي بحوالي V ريات. كما أوضح بيانات نفس الجدول أن متوسط الإحتياجات الفذانية من

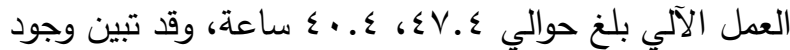
فروق معنوية خلال موسمي الزراعة لاجمالي العمل الآلي. كما تبين وجود فروق معنوية في استخدام العمل الآلي للموسمين وفق العمليات التالية جرار الحرث، ماتور الري، ماتور الرش. في حين تبين عدم وجود فروق خلال موسمي الزراعة لبعض العمليات وهي التسوية بالليزر، السطارة، جرار

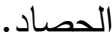

ث.تحليل التكاليف الإنتاجية لفدان البطاطس بمحافظة المنوفية

بإستعراض البيانات الواردة بالجدول (V) تبين أن اجمالي

التكاليف الإنتاجية لفدان البطاطس بمحافظة المنوفية خلال الموسم الصيفي والثتوي بلغ حوالي Y. T. Y. Y. T ألف جنيه علي الترتيب. وتقدر نسبة التكاليف المتغيرة من إجمالي

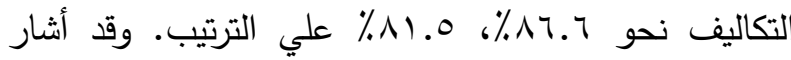
تحليل التباين الي وجود فروق معنوية بين موسمي الزراعة لكل من التكاليف الكلية والتكاليف المتغيرة. وبمراجعة البيانات الواردة بالجدول التالي يتبين أن بنود التكاليف المتغيرة تتوزع

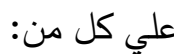

وبالنسبة للأسمدة الأزوتية يحتاج الفدان الي حوالي 179.9 1، r.ب71 وحدة فعالة من الازوت خلال الموسم الصيفي والثتوي علي الترتيب ـ وقدر إحتياجات الفدان بعينة الدراسة من الأسمدة الفوسفاتية والبوتاسية خلال الموسم

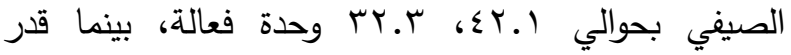
إحتياجات الفدان لكل منهما في الموسم الثتوي بحوالي

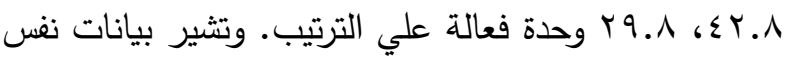
الجدول أن متوسط إحتياجات الفدان من العناصر الصغري خلال الموسم الصيفي والثتوي يبلغ حوالي 0.1، 0.0 علي الترتيب. وقد تبين عدم وجود فروق بين موسمي الزراعة لكلاً من الأسمدة العضوية والكيماوية. r) المبيدات: تشير بيانات نفس الجدول أن متوسط إحتياجات فدان البطاطس بالمنوفية من المبيدات بلغ حوالي Y.Y، Y.0 لتر خلال الموسم الصيفي والثتوي علي الترتيب. وقد تبين وجود فروق معنوية بين موسمي الزراعة. ؛)(العمل البشري والآلكي: بإستقراء بيانات الجدول (†) والذي يوضح متوسط الإحتياجات الفدانية من العمل البشري والآلي، تبين أن متوسط إحتياجات الفدان من العمل البشري خلال

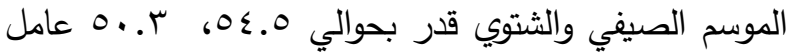
علي الترتيب، وهذا ما يعكسه تحليل التباين من وجود فروق معنوية بين موسمي الزراعة لاجمالي العمل البشري. وقد أوضحت بيانات العينة عدم وجود إختلافات معنوية في إستخدام العمل البشري خلال الموسم الصيفي والثتوي لمعظم العمليات الزراعية، بينما ثبت وجود فروق معنوية في 


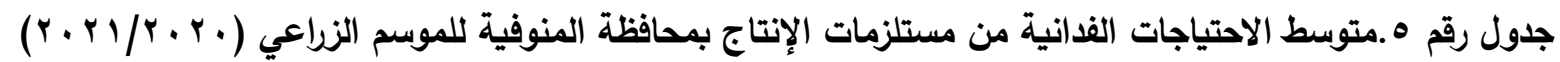

\begin{tabular}{|c|c|c|c|}
\hline التباين & 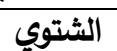 & الصيفى - ل الصي & مستلزمات الإنتاج \\
\hline 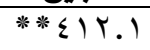 & $1 . \mathrm{V}$ &. .97 & التقاوي طُن \\
\hline. .9 & $r \varepsilon . r$ & $r \leq .1$ & الاسمدة الَّلدية (بم) \\
\hline$r .71$ & 17r.r & 179.9 & اسمدة ازوتية (بالوحدة) \\
\hline. .11 & $\varepsilon r . \wedge$ & $\left.\varepsilon r_{.}\right)$ & اسمدة فوسفاتية (بالوحدة) \\
\hline $1 . \leqslant r$ & r৭.^ & r.r. & اسمدة بوتاسيةً (بالوحدة) \\
\hline Y.TI & צוד & $r \leq \varepsilon . r$ & اجمالى الأسمدة الكيماوية (بالوحدة) \\
\hline..$\varepsilon$ & 0.0 & 0.1 & عناصر صغري (لتر) \\
\hline$* * * 1 \Gamma . \varepsilon$ & V.o & $\Lambda . r$ & مبيدات ومقاومة الآفات (لتر) \\
\hline
\end{tabular}

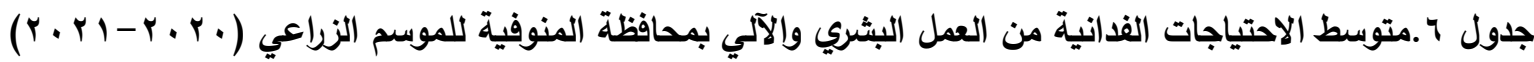

\begin{tabular}{|c|c|c|c|c|}
\hline التباين & الثتوي & الصيفى & \multicolumn{2}{|c|}{ العمليات الزراعية } \\
\hline$\ldots 1$ & Y.A & Y.A & حرث & \\
\hline$\ldots 7$ & 1.4 & $1 . r$ & تسوية & $\overline{3}$ \\
\hline$. .1 \leqslant$ & $r .9$ & «. & الزراعة & 专 \\
\hline$\ldots 1$ & $r .9$ & r.q & التسميد بلدي & $\overline{7}$. \\
\hline$\ldots \varepsilon$ & 0.1 & 0.1 & التسميذ" كيماوي & 象。 \\
\hline. .7 & «.० & $\varepsilon .7$ & التعزيقي & \\
\hline$* * V \leqslant Y$ & v. & $11 . \varepsilon$ & الري & ? \\
\hline. .7 & 9.4 & $\Lambda . \wedge$ & الدكافحة متكاملة & \\
\hline..$r$ & $1 Y .7$ & $1 T .0$ & الحصاد & $\frac{3}{2}$ \\
\hline$* * \% 0.9$ & $0 . . r$ & $0 \leqslant .0$ & اجمالى العمل البشري & \\
\hline. .9 & «.1 & $\varepsilon .0$ & تسوية بالليزر بلري & \\
\hline **ฯ . \& & 纟.V & r. & حرآ حرث & $\overline{3}$ \\
\hline $1 . r$ & r.A & r.V & سطارة & \\
\hline$* *$ * $० 9$ & $1 \vee . \wedge$ & TH.V & ماتور (ي) & 畜 $\frac{3}{4}$ \\
\hline **\% & $\wedge$ & $11 . r$ & ماتور شِ & $\exists$ \\
\hline..$\wedge$ & $\mu$ & $r .1$ & حرار حصاد & 疍 \\
\hline **^ґ.〉 & $\varepsilon \ldots \varepsilon$ & $\varepsilon \vee . \varepsilon$ & إجمالي العمل الآلى & \\
\hline
\end{tabular}

الصصدر : جمعت وحمبت من بيانات العينة الميدانية، نتائج تحليل الثباين بالجدول رقم (") بالملحق. 
أمل كامل عيد رمضان و رانيا عبدالله السعيد طلبة: دراسة تحليلية لسلسلة القيمة لمحصول البطاطس بمحافظة المنوفية 643

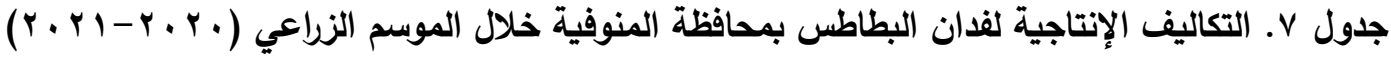

\begin{tabular}{|c|c|c|c|c|c|}
\hline التباين & $\%$ & الشتوي & $\%$ & الصيفي & العملية الزراعية \\
\hline **ฯマท & YY.V & VYVO & «ะ.ร & $|V| K \mid$ & التقاوي \\
\hline$* * *_{\ldots}$ & r.^ & Vos & r.V & $1 \cdot r$. & الاسمدة آلَّلدية \\
\hline r. & 9.9 & หч人q & V.r & rVVT & الاسمدة ازوتية \\
\hline .11 & r.o & $9 \leq 1$ & r.乏 & qrV & اسمدة فوسفاتية \\
\hline .97 & 1.r & ז & $1 .$. & r9० & اسمدة بوتاسية \\
\hline .90 & $r .9$ & 1.7. & r.l & I11 & عناصر صغري \\
\hline$* 9.1$ & r. & 091 & $1 . v$ & TVO & مبيدات ر \\
\hline **ฯ. & $0 . . r$ & . & Tr.O & $r \varepsilon) \cdot V$ & اجمالى قيمة مُّتلزمات الإنتاج \\
\hline$* * r_{0}$ & r..r & $10 \ldots$ & $r \leq .1$ & 94.0 & اجمآلى قيمة العمل " - \\
\hline$* *\rceil \varepsilon$. & 11.0 & YrIA. & 1.. & Trधा & اجمالى التكالَيف المتغيرة \\
\hline .7 & 10.1 & $\varepsilon 1 \cdot r$ & 1.00 & $\varepsilon .7 \wedge$ & قايمة الإيجار "قال \\
\hline$* * \wedge \vee \cdot \vee$ & r.乏 & $91 \%$ & r.^ & $1.0 r$ & قيمة تكاليفَ التعبئة \\
\hline$* * \nearrow \leq \nearrow$ & $1 \ldots$ & TVYIT & $1 .$. & rNT. & قيمة تكالّيف الإنتاج الكلية للفدان \\
\hline$* * \varepsilon \wedge$. & - & Ir.人 & - & $1 v .00$ & متوسط إنتاجية الفذان (طن) \\
\hline$* \varepsilon$ & - & rוT & - & rTII & متوسط تكلفة الطن \\
\hline- & - & YIT & - & r... & سعر التعادل \\
\hline
\end{tabular}

الصصدر : جمعت وحسبت من بيانات العينة الميدانية، نتائج تحليل التباين بالجدول رقم (ع) بالملحق.

حوالي YVVY، rVY

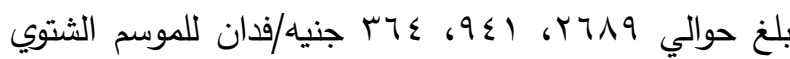
علي الترتيب. وبإجراء إختبار التباين تبين عدم وجود فروق

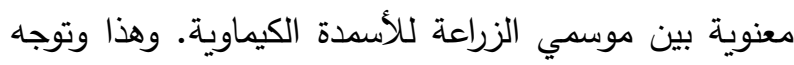
الدولة دعم للاسمدة الازوتية تقدر بحوالي ع شيكارة/فدان

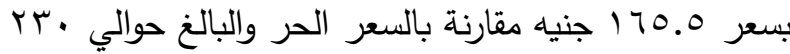
جنيه/شيكارة في المتوسط.

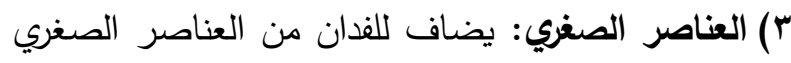

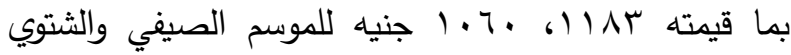
علي الترتيب. وبإجراء إختبار التباين تبين عدم وجود فروق لهايه

$$
\text { معنوية بين موسمي الزراعة. }
$$

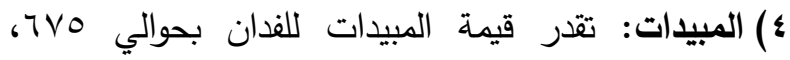

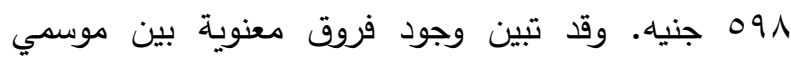

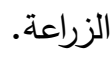

•) اجمالي قيمة مستلزمات الإنتاج: قدر متوسط قيمة

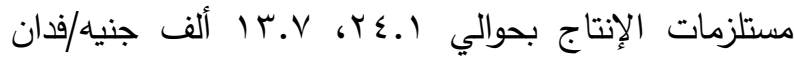

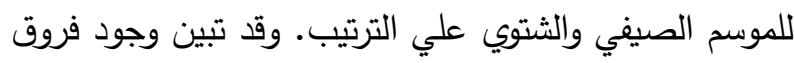
معنوية خلال موسمي الزراعة.
1) التقاوي: مما لاشك فيه أن من أهم مشاكل إنتاج محصول البطاطس في مصر هو ارتفاع أسعار التقاوي

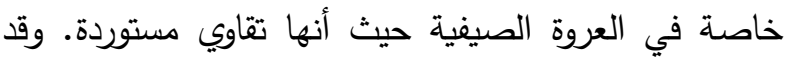

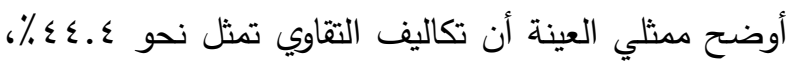

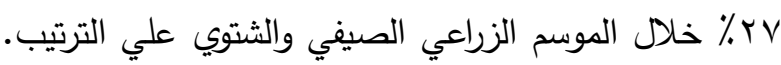

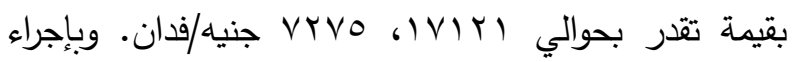
إختبار التباين تبين وجود فروق معنوية بين أسعار التقاوي خلال موسمي الزراعة. هذا وقد أوضح مدثلي العينة إنخفاض أسعار التقاوي للموسم الثتوي لهذا العام مقارنة

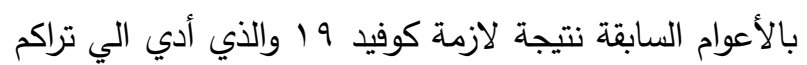
إنتاج البطاطس الصيفي ووفرة في التقاوي المتداولة.

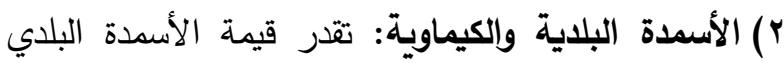

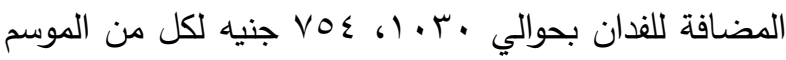

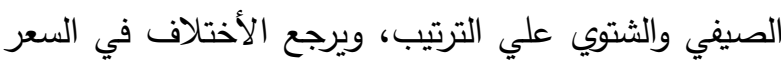

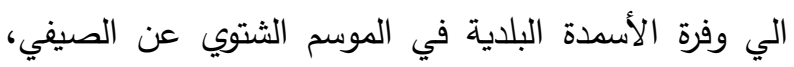
وهو ما يعزي الي انخفاض سعره، وبإجراء إختبار التباين تبين وجود فروق معنوية بين موسمي الزراعة. وقد بلغ قيمة الأسمدة الأزوتية والفوسفاتية والبوتاسية للموسم الصيفي 
ت. تحليل مخرجات الإنتاج لفدان البطاطس بمحافظة المنوفية

بإستعراض البيانات الواردة بالجدول (^) والخاص

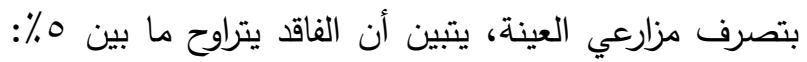
• ٪\%، وقدر متوسط الفاقد لمزارعي العينة خلال الموسم الصيفي بنحو \٪، في حين يزداد الفاقد خلا الموسم

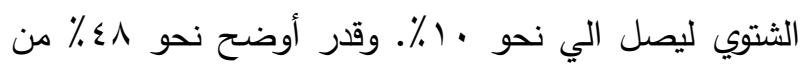
مزارعي العينة للموسم الصيفي بالاحتفاظ بجزء من الإنتاج

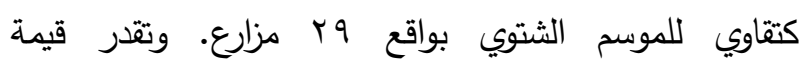
الاستهلاك العائلي والهدايا بنحو ب٪ خلال موسمي الزراعة بكمية تبلغ حوالي • بr، • بr كيلو/فدان. وعليه تقدر الكمية

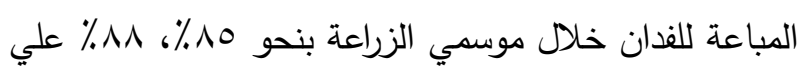

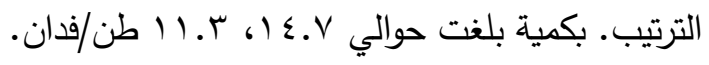
وقد أوضح مزارعي العينة أن عمليات الفرز والتعبئة يتحملها المزارع ضمن تكاليف الإنتاج، وتتمثل تكلفة التعبئة في توفير أجولة بلاستيكية سعة ، ج : V كجم يتراوح سعرها

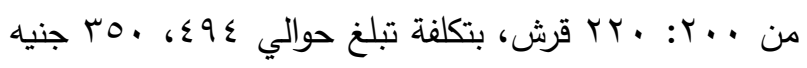
للفدان لكل من الموسم الصيفي والثتوي علي الترتيب. وذلك لتك نتيجة للإختلاف في عدد الأجولة وفق الإنتاجية الفدانية. وتقدر تكلفة التعبئة بحوالي OA1، باهية جنيه/فدان نظير أجر عاملين للتعبئة والربط. وقد تبين وجود فروق معنوية بين موسمي الزراعة لاجمالي تكاليف التعبئة وهذا ما أشار اليه

$$
\text { جدول (V) أعلاه. }
$$

†) قيمة العمل: يقدر متوسط قيمة العمل (البشري والآلي)

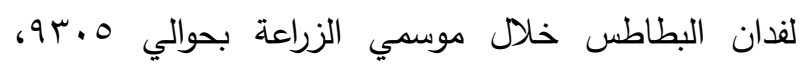
خلم جنيه علي الترتيب. وقد تبين وجود فروق معنوية خلال الموسم الصيفي والثتوي. ( الإيجار: يبلغ متوسط قيمة الإيجار للموسم الصيفي

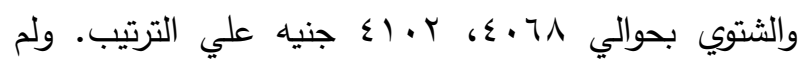
تثبت وجود فروق معنوية خلال موسمي الزراعة حيث يتراوح

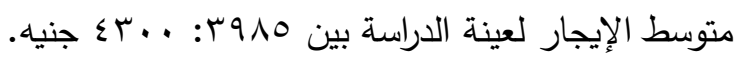

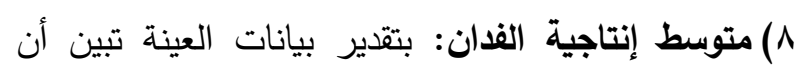
متوسط إنتاجية العينة خلال الموسم الصيفي بلغ حوالي IV.7 طن. وقد بلغ أقصي إنتاجية فدانية بقرية سرس الليان

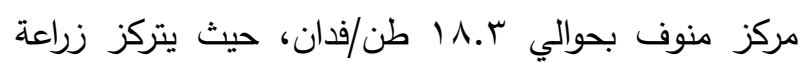

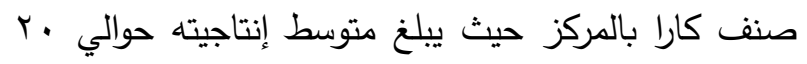
طن/فدان. بينما بلغ أدني إنتاجية بقرية البرانية بمركز أشمون

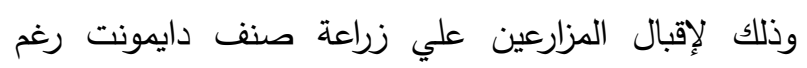
إنخفاض إنتاجيته ويبلغ متوسط إنتاجيته حوالي 17 طن/فدان. وبالنسبة للموسم الثتوي بلغ متوسط إنتاجيه العينة حوالي ^.r ا طن/فدان. وقد بلغ أعلي إنتاجية بقرية فيشا بمركز منوف بمتوسط قدر بحوالي هوبا بان طن/فدان، بينما بلغ أقل إنتاجية فدانية بقرية البرانية بمركز أشمون بحوالي

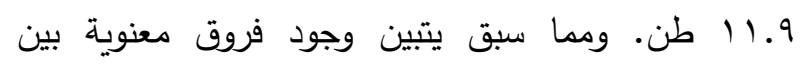
الإنتاجية الفدانية لموسمي الزراعة وهو ما أوضحة تحليل التباين.

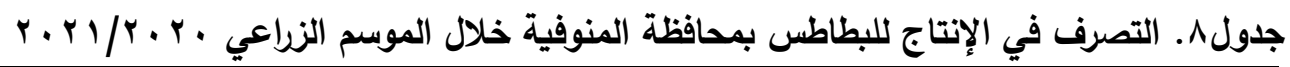

\begin{tabular}{|c|c|c|c|c|c|c|c|}
\hline تكلفة أدوات التعبئة & التعبئة & الإنتاج المباع & استهلاك عائلي وهدايا & تقاوي & 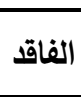 & الإنتاجية & 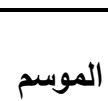 \\
\hline \multicolumn{2}{|c|}{ جنيه/فدان } & \multicolumn{5}{|c|}{ كمية (طن/فدان) } & \\
\hline$\leq 9 \leq$ & $\Delta \wedge \wedge$ & $1 \leqslant . V$ &. .47 & $1 . r$ & $1 . r$ & $1 V .7$ & الصيفى \\
\hline ro. & OTr & $11 . r$ &..$r \mu$ & - & $1 . r$ & IY.A & الشتوي \\
\hline
\end{tabular}


أمل كامل عيد رمضان و رانيا عبدالله السعيد طلبة: دراسة تحليلية لسلسلة القيمة لمحصول البطاطس بمحافظة المنوفية 645

ويرجع ذلك لعدم إلتزام بعض الموردين بالأسعار المتفق

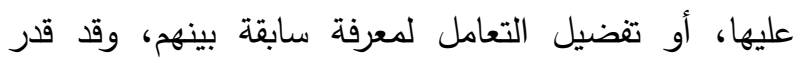

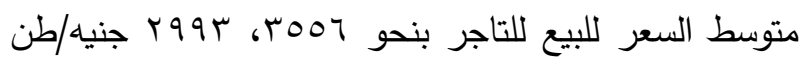

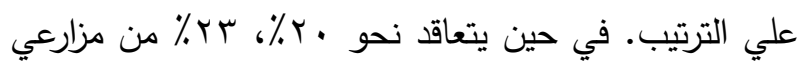

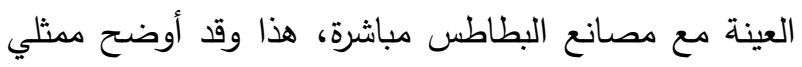

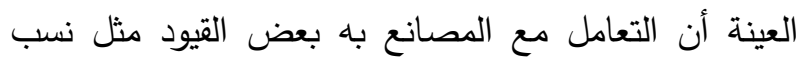

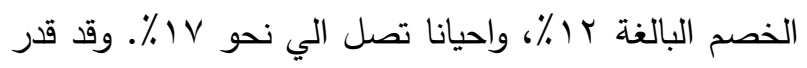

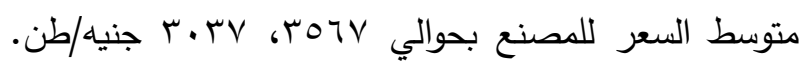

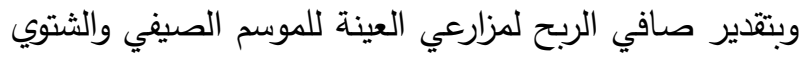

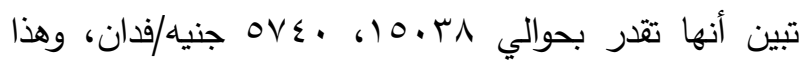

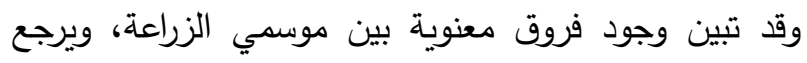
لاختلاف متوسط الإنتاجية، وأسعار التقاوي.

ح.تحليل سلسلة القيمة للجهات الفعالة: بإستعراض الثكل التخطيطي التالي لسلسلة القيمة لكحصول البطاطس بمحافظة المنوفية، يتبين أن السلسلة

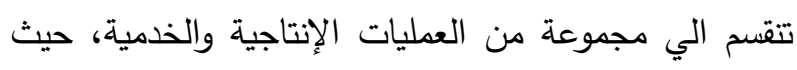

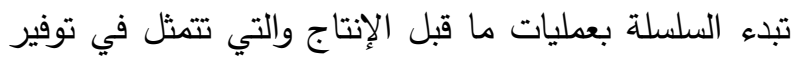
مستلزمات الإنتاج للححصول. والفئات المسئولة عن هذاته

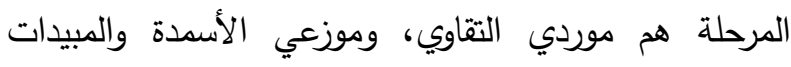

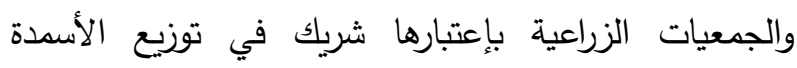

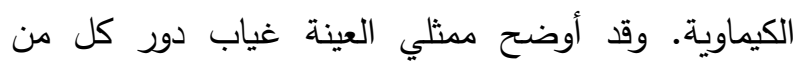

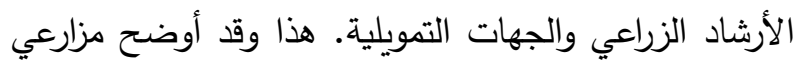

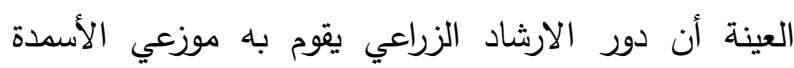

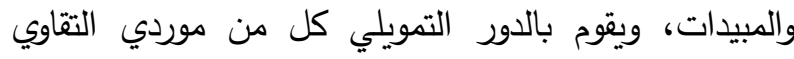
وموزعي الأسمدة وذلك بالبيع بالآجل لددة r شهور بنسبة

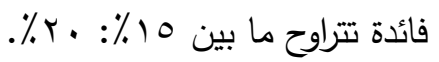

ج.تحليل إيرادات إنتاج فدان البطاطس بحافظة المنوفية

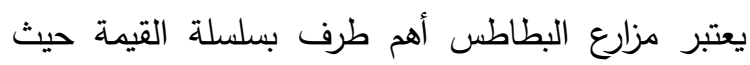
يتحمل العبء الأكبر من الجهد والمخاطرة. حيث يتحكم في المزارع قوي الطلب والمتمثلة في الموردين وتجار الجملة وأصحاب المصانع، ويتجنب مزارعي العينة البيع لتجار التجزئة نظراً لكثافة الإنتاج، وهو ما يجعلهم أكثر عرضهابه للضغوط المادية من قبل المشترين. وبإسترجاع البيانات الواردة بالجدول (V) يتبين أن متوسط لئنس

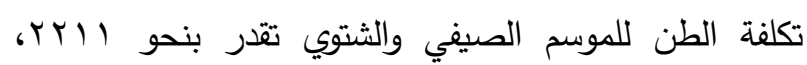
اسT Y جنيه علي الترتيب، وقد تبين وجود فروق معنوية بين

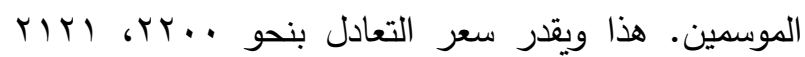
جنيه/طن.

وبدراسة إيرادات المزارع من خلال بيانات الجدول (9) يتبين وجود r جهات فعالة للتعامل، منها البيع للموردين،

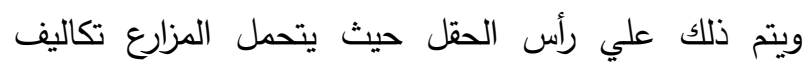

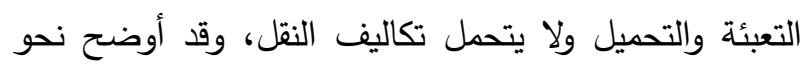

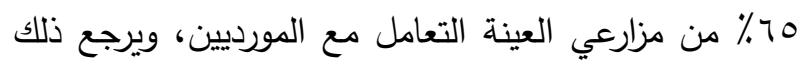
لعدم وجود نظم لربط المزارعين بالأسواق، بالإضافة الي تقليل

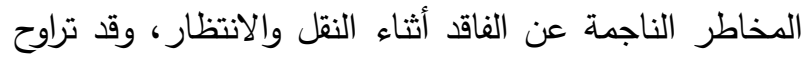

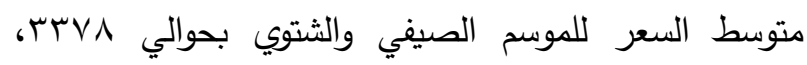

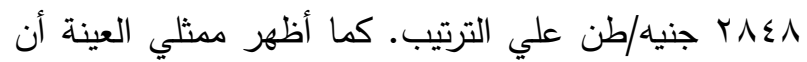

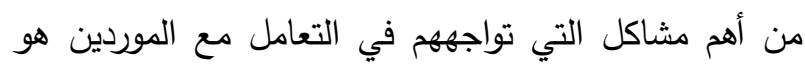

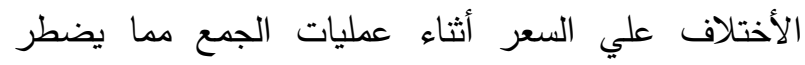

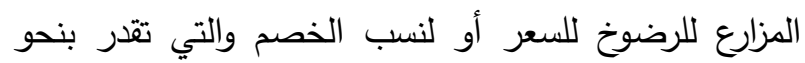

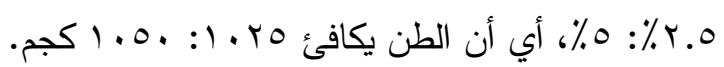

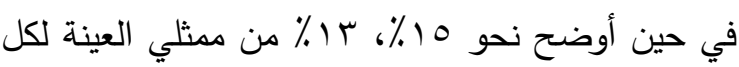

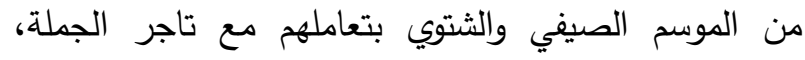




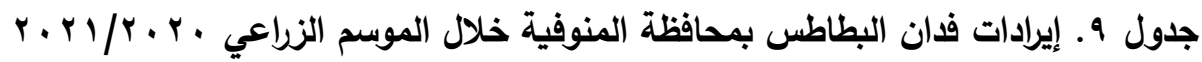

\begin{tabular}{|c|c|c|c|c|c|c|c|c|}
\hline \multirow{2}{*}{ صنية/فيدان } & \multirow{2}{*}{ جنيهلة فالإيراد } & \multicolumn{2}{|c|}{ البيع للمصنع } & \multicolumn{2}{|c|}{ البيع لتاجر الجملة } & \multicolumn{2}{|c|}{ البيع للموردين } & \multirow[b]{2}{*}{ الموسم } \\
\hline & & م. سعر الطن & \% من العينة & م. سعر الطن & \% من العينة & م. سعر الطن & \% من العينـة & \\
\hline 10.41 & Oryos & roTr & $r \cdot$ & $r 004$ & 10 & rTVA & 10 & الصيفي \\
\hline OV $\leqslant$. & rraAr & $r \cdot r v$ & r & raq & ir & $Y \Lambda \leqslant \Lambda$ & I & الشتوي \\
\hline
\end{tabular}

المصدر : جمعت وحسبت من بيانات العينة الميدانية.

أوضحوا أن نسب الاشغال تبلغ نحو •V\%، باستثاء الموسم الصيفي الحالي فقد تزايد نسب الاشغال لتصل

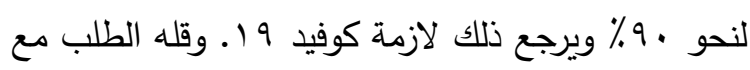

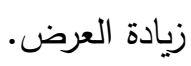

r. موردين (وسطاء): يتعامل نحو \% \% \% من مزارعي العينة

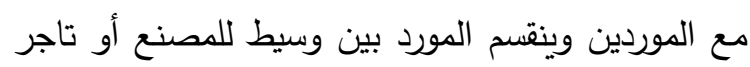

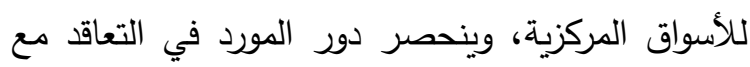

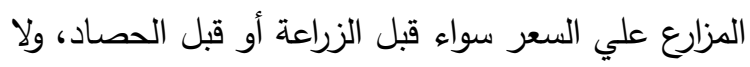

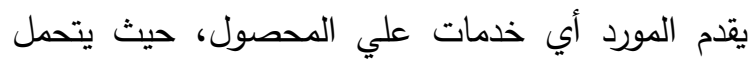
المزارع تكاليف التعبئة والتحميل، ويقدر ربح المورد بنحو Tن ج...

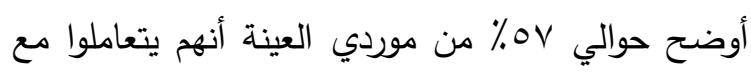

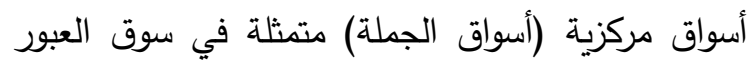
وسوق 1 أكتوبر وسوق الحضرة. ويتحمل المورد تكلفة

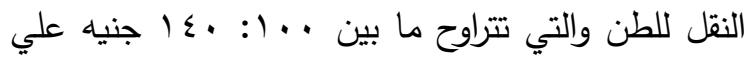

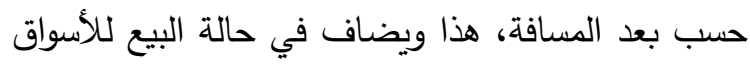

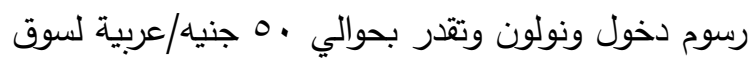

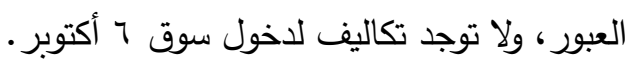

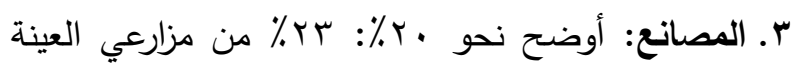

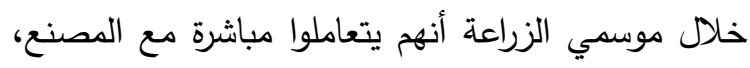

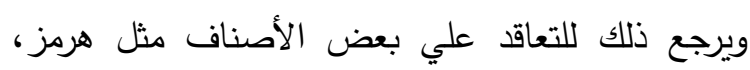

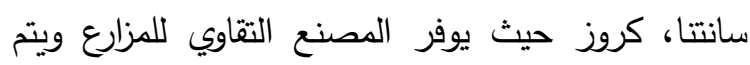

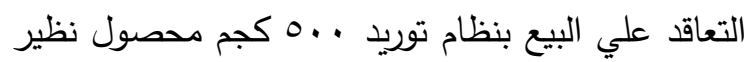

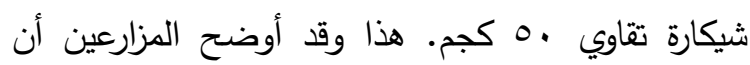

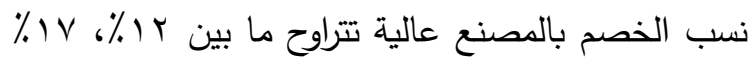

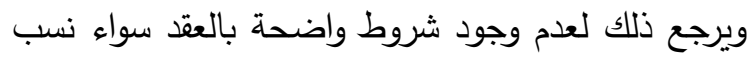

تلي عمليات ما قبل الإنتاج عملية الإنتاج والفاعل الرئيسي بها هو المزارع. وقد أوضحي مزارعي العينة أن الإنتاج

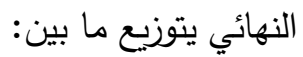

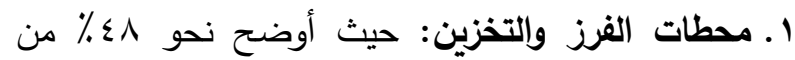

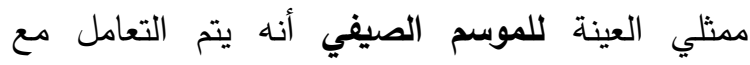

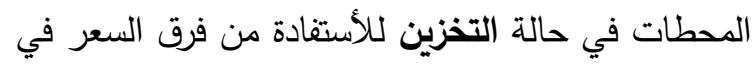
نهاية الموسم والذي يرتفع نتيجة فجوة الطلب والعرض، أو التخزين البطاطس كتقاوي للموسم الثتوي، بنسبة تمثل فئل

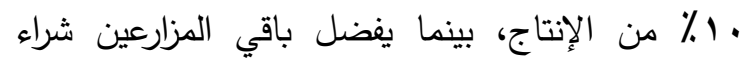
التقاوي للموسم الشتوي وعدم تحمل تكاليف نقل للثلاجات

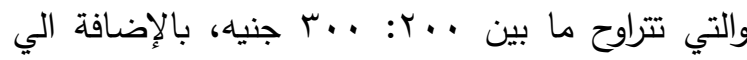
تكاليف التخزين والتي تتراوح ما بين . . ؟ا: ..

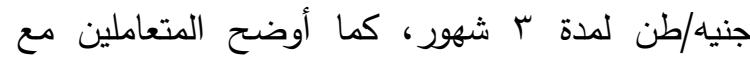
الثلاجات أن من أهم مشاكلها أرتفاع نسب الإصابة والتي التي

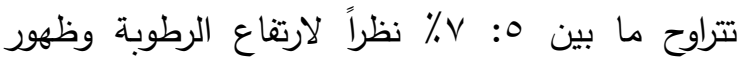

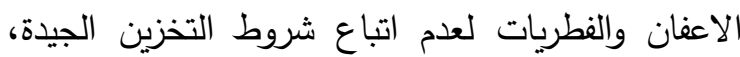

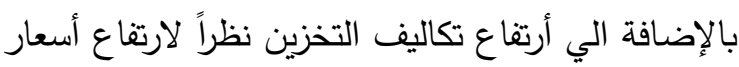

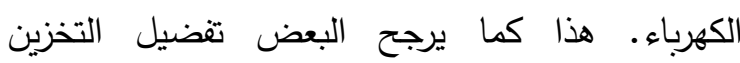

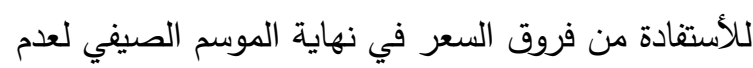
توافر كميات كبيرة من المحصول، وعلي هذا يقوموا بتخزين البطاطس بالنوالات للدة 10 يوم مع الفرز والتقليب المستمر ثم التعبئة والنقل الي الثلاجات. أما لئا بالنسبة للموسم الثتوي فقد أوضح ممثلي العينة عدم التبن

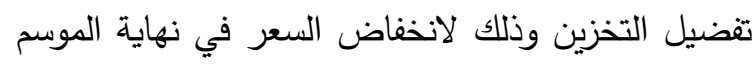
تزامنا مع بدء ظهور إنتاج العروة الصيفي. وبسؤال

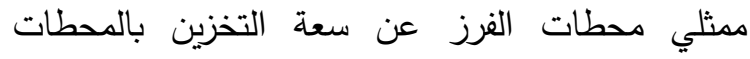


أمل كامل عيد رمضان و رانيا عبدالله السعيد طلبة: دراسة تحليلية لسلسلة القيمة لمحصول البطاطس بمحافظة المنوفية 647

السعر قبل عمليات الجمع وبعد الآتفاق مع العمالة المسئولة عن الحصاد والتعبئة. وعليه يضطر المزارع

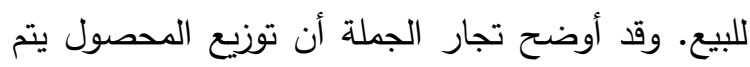
داخل أسواق القرية والقري والمجاور عن طريق التوزيع للوكالات أو تجار التجزئة ومنها الي المستهلك النهائي النهائي.

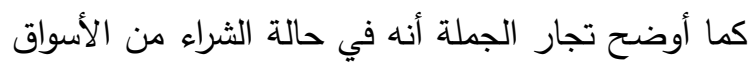

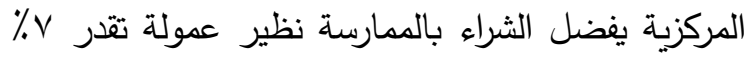
عن نظام الشراء بالمزاد. ه. تاجر التجزئة: لم يظهر حلقة ترابط بين تاجر التجزئة

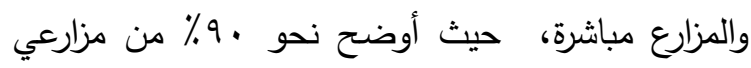
العينة صعوبة بيع البطاطس لتجار التجزئة مباشرة، وذلك مناتك

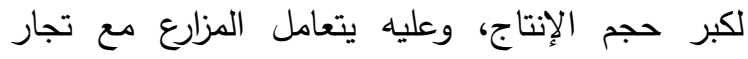

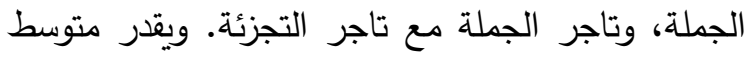
سعر التداول لتاجر التجزئة لكل من الموسم الصيفي

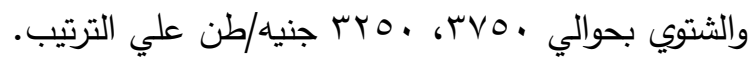

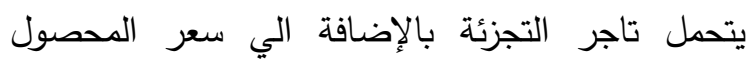
تكاليف النقل وتكاليف رسوم الخروج من الأسواق المركزية والتي تقدر بحوالي ·1 جنيه/عربية بالإضافة الي تكاليف الفرش أو الارضية بالأسواق المحلية والتي

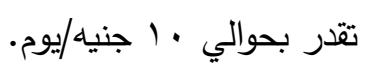

צ. الاستهلاك العائلي والهايا: يقدر نسبة الاستهلاك

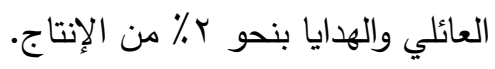

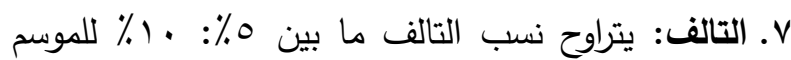
الصيفي والثتوي علي الترتيب، وقد أوضح ممثلي العينة أن الفاقد يتم بيعه لمربي المواشي نظير ل .با: . .ـ جنيه/طن أو استخدامه كأعلاف للحيوانات المملوكة لتطيل

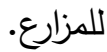

الخصم أو الموصفات الفينة للثرة، هذا بالإضافة الي وجود نسب فاقد في المحصول نتيجة الإنتظار أمام المصنع. ويتحمل في هذه الحالة المزارع تكاليف النقل

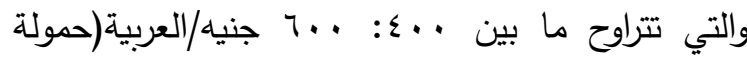
العربية تتراوح ما بين 0: > طن). كما أوضح المزارعين

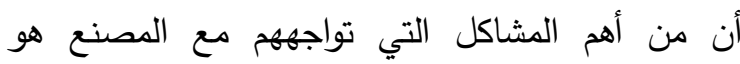

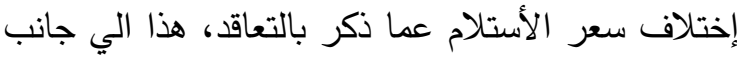
إلتزام المصنع بالكمية المتفق عليها بالسعر المتعاقد عليه، وفي حالة شراء كميات إضافية يتم بالسعر الحر بالهر

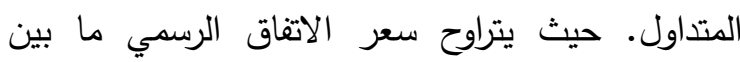

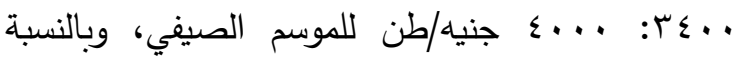

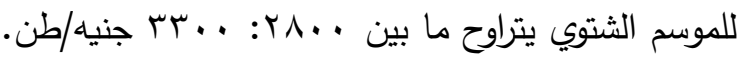

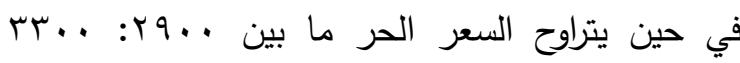

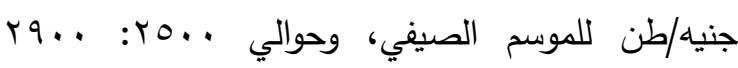
للموسم الثتوي. وقد أوضح مديري المصانع المدروسة لمدية

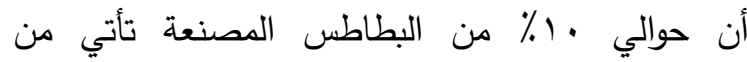

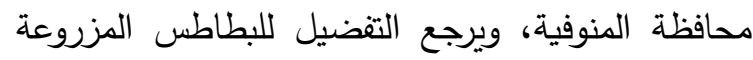
في الاراضي الصحراوية هي نظافة الثمرة من الطمي لناري مقارنة بالاراضي القديمة. وتبلغ نسب تداول المنتج (بطاطس نصف مقلية ورقائق) في السوق المحلي بنحو

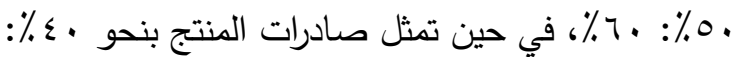

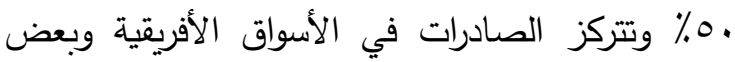

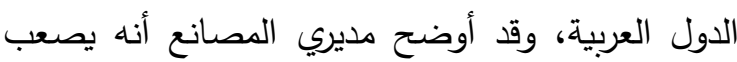

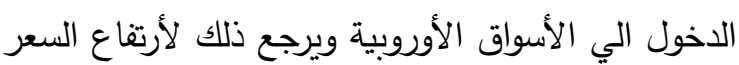

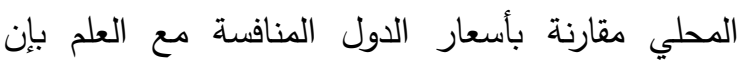
الجودة متماثلة، ويرجع ذلك الي أرتفاع اسعار مستلزمات

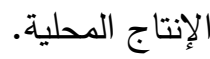

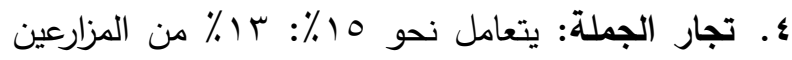
خلال موسمي الزراعة مع تجار الجملة بالمنطقة، ويتم التعامل مع هؤلاء التجار نظير توفير التقاوي والاسمدة بالآجل. وقد أوضح بعض المزارعين أنهم يكونوا تحت

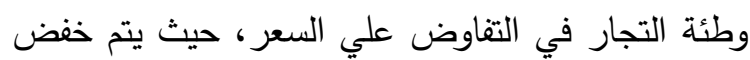




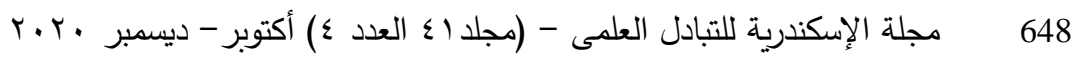

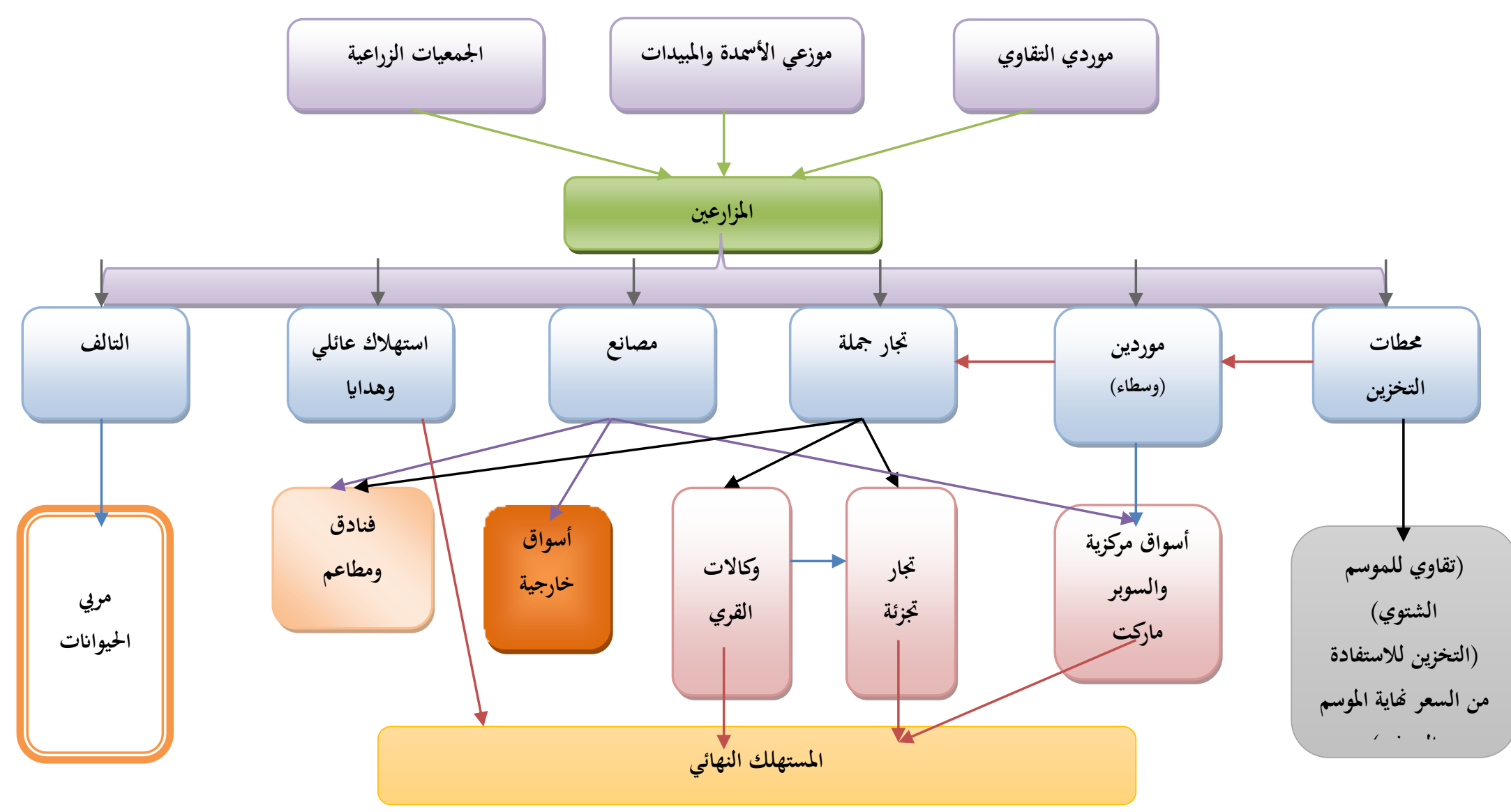

الثكل التخطيطي ا. سلسلة القيمة للبطاطس بمحافظة المنوفية

المصدر : صممت بناء علي نتيجة الإستبيان من قبل الباحثين 
أمل كامل عيد رمضان و رانيا عبدالله السعيد طلبة: دراسة تحليلية لسلسلة القيمة لمحصول البطاطس بمحافظة المنوفية 649

بحوالي 0؛ عامل ( ·r دائم+ 10 مؤقت)، ويبلغ متوسط الطاقة الإنتاجية للمصانع بحوالي • v طن/يوم. وتمثل نسبة

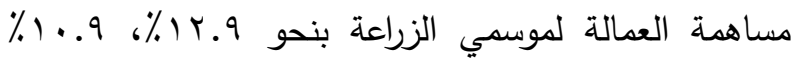
علي الترتيب من اجمالي العمالة علي طول السلسة. وعليه

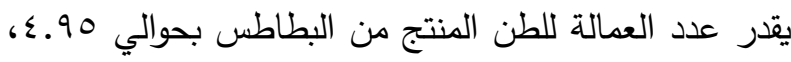

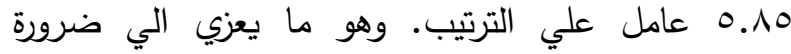
الاهتمام بهذا المحصول والعمليات التسويقية الدقامة عليه لأرتفاع نسب التثغيل به.

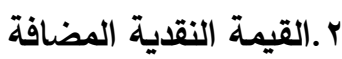

بإستعراض سلسلة القيمة للمتعاملين عليها، يتبين أن القيمة النقدية المضافة للمزارع تقدر بحوالي 1OV، جنيه/طن خلال الموسم الصيفي والثتوي علي الترتيب،

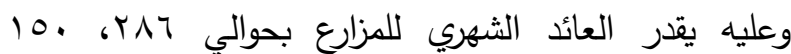
جنيه/طن. بالنسبة للمورد فإن صافي العائد يقدر بحوالي لئي 1... . . . جنيه/طن، وتتمثل في تكاليف النقل والنولون، ويتحصل

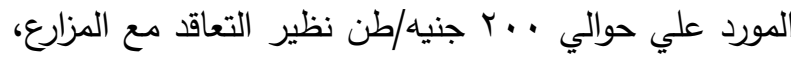

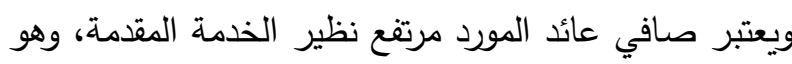
ما يضعف من ربح المزارع نتيجة لتعدد المشاركين في عمليات التسويق.

فo. في حين يقدر إيراد تاجر الجملة بحوالي جنيه/طن، وتتمثل التكاليف المنفقة من قبل التاجر في النقل والتخزين والنولون والفرز والحراسة بحوالي • با جنيه/طن، وعليه يقدر صافي عائد الطن بحوالي • rا جنيه. وبالنسبة

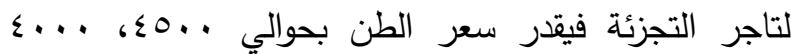
جنيه، وتقدر قيمة التكاليف المنفقة من تحميل ونقل واجره

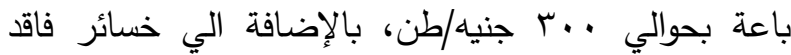
تقدر بحوالي ..1 جنيه/طن، وعليه يقدر صافي ربح تاجر

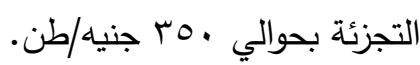

بالنسبة للمصانع ووفق بيانات الإنتبيان تبين أن تكلفة الطن المصنع للبطاطس النصف مقلية والرقائق يقدر بحوالي
خ.القيمة المضافة علي محصول البطاطس تعتبر القيمة المضافة أحد أعمدة الاقتصاد السياسي، فالسلعة التي يتم عمل قيمة مضافة لها تُريد من الطلب عليها وبالتالي تزداد أرباحها. وتعرف القيمة المضافة بإنها هي مجموعة العمليات التي تقام علي المحصول لإنتاج منتجات اخري ذات قيمة اقتصادية وغذائية. وتحسب بمجموع المنافع مقسوماً علي مجموع التكاليف لمستلزمات الانتاج.

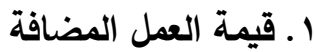

بمراجعة فرص العمل التي يوفرها محصول البطاطس خلال السلسلة الإنتاجية، تبين ان عدد العمالة الزراعية لإنتاج الطن من محصول البطاطس الصيفي والثتوي يقدر بحوالي r.T، Y.؟ عامل علي الترتيب. حيث ييلغ عدد عمالة

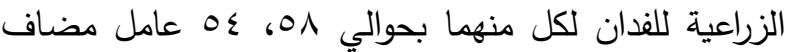
اليها عمالة الفرز والتعبئة بالحقل (r عامل/فدان)، وبحساب لاندان نسبة مساهمة العمالة الزراعية بسلسلة الإنتاجية تبين أنها

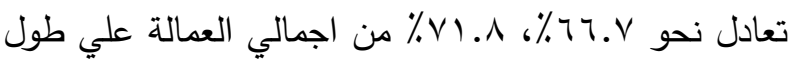
السلسلة لموسمي الزراعة علي الترتيب. وبالنسبة لموردين المصانع فيقتصر دور العمالة علي النقل من المزرعة والتتريخ أمام المصنح، وقدر عدد العمالة

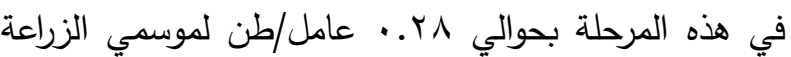
وهذا بموجب r عامل/عربية، ويقدر نسبة مساهمة العمالة

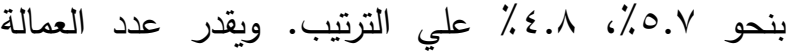
بالنسبة لتاجر الجملة بحوالي ז.. العمالة في عمليات النقل والتخزين والحراسة، وتعادل نسبة العمالة نحو 1.7\%؛ 0.1\% من اجمالي العمالة علي طول السلسلة. بينما قدر عدد العمالة لتاجر التجزئة لكل طن التهالئ بحوالي بـ.. عامل، وذلك نظير عمليات النقل والبيع المباشر للمستهلك، ويبلغ نسبة مساهمة تاجر التجزئة بنحو التحالي

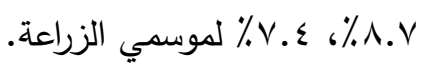

في حين يقدر عدد العمالة بالمصنع بحوالي ؟آ. عامل/طن، حيث يقدر متوسط العمالة بالمصانع المدروسة بلعالي 


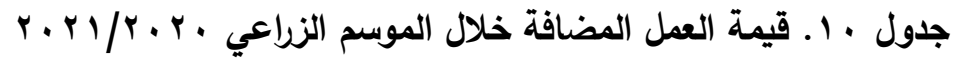

\begin{tabular}{|c|c|c|c|c|c|c|c|c|c|c|c|}
\hline الاجمالي & $\%$ & المصنع & $\%$ & التجزئة & $\%$ & تاجة & $\%$ & للمصارديع & $\%$ & المزرعة & الموسم \\
\hline$\{.90$ & 17.9 & צ & A.V &..$\leqslant \Gamma$ & 7.1 &.$r$ & $0 . V$ &.$Y \wedge$ & $74 . V$ & r.r & صيفى \\
\hline 0.10 & 1.99 & צ & $V . \varepsilon$ &..$\leqslant r$ & 0.1 & r. & \&.A & ג & VI.A & \&.Y & شتوي \\
\hline
\end{tabular}

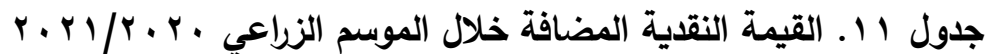

\begin{tabular}{|c|c|c|c|c|c|}
\hline المصنع & تاجر التجزئة & تاجر الجملة & الموردين & المزرعة & الموسم \\
\hline $11 \ldots$ & ro. & ir. & $1 \ldots$ & $\begin{array}{l}\text { 10V } \\
\leqslant 01\end{array}$ & شتيفى \\
\hline
\end{tabular}

المصدر : جمعت وحسبت من بيانات العينة الميانية.

الخارجية وهي تثمل نقاط الفرص، ونقاط التهديدات. وعليه يهدف التحليل الرباعي الي التركيز على نقاط القوة، ومعالجة نقاط الضعف، والإستفادة من الفرص المتاحة، ومواجهه التهديدات التي تواجه السلسلة. وبإستعراض الثكل التخطيطي (r) والذي يوضح نتائج تحليل SWOT وفق لآراء مبحوثي العينة الميدانية والتي تم تتاولها بناء علي أهم المشاكل الإنتاجية والتسويقية التى لاء تواجههم بالإضافة الي أهم الفرص التي يمكن الاستفادة منها للنهوض بالمنتج وتحقيق دخول أعلي للمتعاملين معاه علي طول السلسلة الإنتاجية والتسويقية. حيث يعتمد نتائج التحليل علي التمثيل البياني علي الدحور السيني والذي يمثل نقاط الإختبار هل هي نقاط القوة

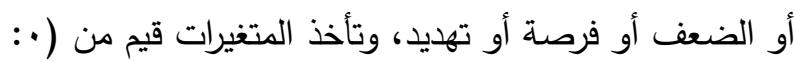
0) وفق مدي القوة والتأثير ويتراوح الددي ما بين قوي التيات ومتوسط وضعيف ويأخد قيمة صفر إذا كان محايد، بينما يمثل المحور الصادي مدي احتمالية وصلة هذه الإختبارات وتأخذ أيضاً المتغيرات قيم من (·: 0) وفق مدي الاحتمالية أو الصلة ويتراوح الددي ما بين قوي ومتوسط وضعيف الفيف ويأخد قيمة صفر إذا كان محايد. وتمثل حجم الفقاعة تاثير لإير هذه النقاط، وتتحدد حجم الفقاعة وفق القيم من (1:
T ألف جنيه، في حين يقدر سعر تداول المنتج في الأسواق المحلية بحوالي بr ألف جنيه/طن (هايير ماركت، كارفور، خير زمان)، وعليه يقدر صافي عائد القيمة النقدية للمصنع بحوالي لا ألف جنيه، وتتمثل المصروفات الإنتاجية للمصنع في اقساط إهلالك وتكاليف إيجارات وعمالة وزيوت ومعدات. وبمراجعة عوائد الأطراف المشاركة في العملية الإنتاجية يتبين أن أرباح الوسطاء تفوق أرباح المنتجين،

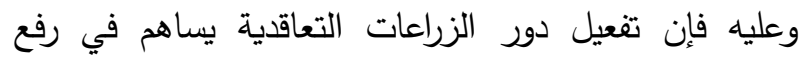
مستوي دخول المزارعين وضمان ربحية عادلة للمزارع وذلك وفق عقود ملزمة لكل الأطراف.

r.التحليل الرباعي لسلسة القيمة للبطاطس بمحافظة لإطة

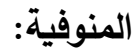

يعتبر التحليل الرباعي (SWOT) أسلوب تحليلي يهدف الي معرفة نقاط القوة والضعف ومعرفة الفرص والتهديدات التي تواجه السوق. وهو من أفضل النظم لبناء إستراتيجيات

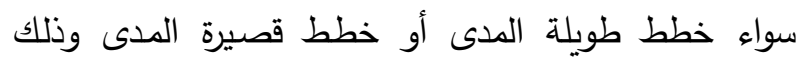
للوصول إلى الأهداف المنشودة، بتحليل مجموعة المتغيرات التي تؤثر بثكل مباشر أو غير مباشر علي المنتج. وتتقسم

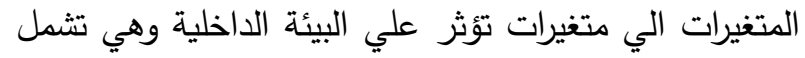
نقاط القوة، ونقاط الضعف. ومتغيرات تؤثر علي البيئة 
أمل كامل عيد رمضان و رانيا عبدالله السعيد طلبة: دراسة تحليلية لسلسلة القيمة لمحصول البطاطس بمحافظة المنوفية 651

وتتمثل أهم نقاط الضعف من حيث الأهمية والتاثير

الإستراتيجي أرتفاع أسعار مستلزمات الإنتاج، وهذا ما مال أوضحه جميع فئات المبحوثين آثر ذلك علي التداول والتصنيع. ويتساوي تأثير كل من أرتفاع نسب المخاطرة الإنتاجية والتسويقية، مشكلة التفتت الحيازى، عدم وجود ولمدئ روابط للمنتجين حيث أنهم ذات تاثير استيراتيجي متوسط. ويمثل تأثير ارتفاع نسب الفاقد والتالف تأثير متوسط وذلك

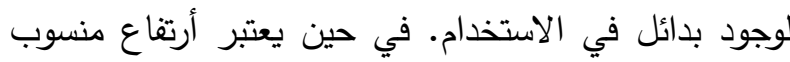

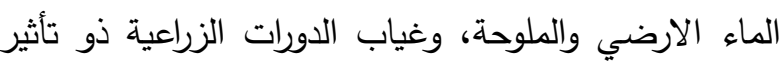
محدود لقربهم من المحور الافقي والرأسي. وتأتي التهديدات كأحد العوامل الخارجية المؤثرة علي المنتج وتتعدد نقاط التهديد نظرا لتشابك المتعاملين والجهات المرتبطة بالإنتاج، ويأتي ضعف الدور الإرشادي والتعاوني كأهم التهديدات ذات التأثير المرتفع علي السلسلة. يليه تأثير كل من زيادة عدد الوسطاء، مناخ غير جيد للإنتاج بمعايير جودة عالمية، ويرجع ذلك لتبقي آثر العفن البني بالأراضي القديمة علي الرغم من القضاء عليه بالرش أثناء رية بردية

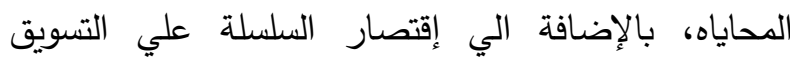
الداخلي والتصنيع. وتتساوي في التاثير المتوسط كل من

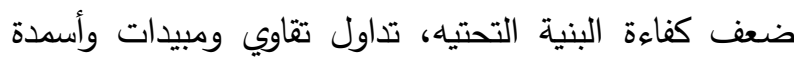
مغشوشة، عدم وجود عقود ملزمة بين المزارعين والوسطاء، إحتكار مستوردي تقاوي البطاطس. في حين يتبين أن التأثير الإستيراتيجي الأقل علي السلسلة لكل من ضعف الخدمات التسويقية والمعلوماتية، التغيرات المناخية. ويرجع عدم تآثر الثرن المزارعين بالتغيرات المناخية الي الخبرة العالية في الزراعة مما يساعدهم علي تحديد الفترة المثلي في الزراعة ( الموسم الصيفي من أخر ديسمبر الي أول يناير، الموسم الثتوي من أخر سبتمبر الي أول أكتوبر).

وتعتبر الفرص المتاحة أهم داعم للمحصول فيعتبر تفعيل دور المؤسسات القومية والمتمثلة في الجمعيات التعاونية والزراعات التعاقدية أهم المتغيرات تاثيراً علي المحصول،
ويتراوح المدي ما بين قوي ومتوسطوضعيف، وعليه كلما زاد حجم الفقاعة كلما اشار الي مدي أكبر للمتغير • ويحدد قرب وبعد الفقاعة عن المحور درجة أهمية المتغير، حيث يتم تصنيف تلك الموجودة بالقرب من (·، •) هي الأقل أهمية والعكس كلما بعد عن المحور كان التاثير اكبر. وبإستقراء باستقراء الثكل التخطيطي r أدناه يتبين أن

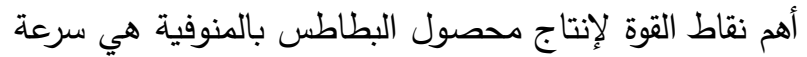
دوران رأس المال، وهو ما أكده مزارعي العينة في تفضيل زراعة محصول البطاطس مقارنة بالمحاصيل الحقلية حيث لا لهابل تزيد فترة الزراعة عن r شهور، وكذلك بالنسبة للتجار والمصنعين نظراً للاقبال علي المنتج باستثناء الفترة الحالية نظراً لجائحة كورونا حيث أدي الي انخفاض معدلات الطلب خاصة بالنسبة للطلب الخارجي والذي أثر علي طلب المحلي وذلك بزيادة المعروض من ناتج الأراضي الجديدة والذي ينخفض سعره مقارنة بسعر الأراضي القديمة (حيث أوضح

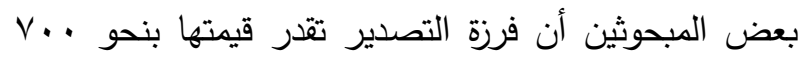
جنيه/طن) وهي كفيلة بتغطية إحتياجات السوق المحلي، هذا بجانب انخفاض الطلب المحلي والمتمثل في الفنادق والمطاعم والمدارس. وتتساوي في التأثير كل من توافر الخبرة في الزراعة وتوفير فرص عمل. وعلي الرغم من إعتبار ممثلي العينة أن محصول البطاطس محصول استراتيجي وقومي، وهي أحدي نقاط القوة، الإ أنها تقترب من المحور الأفق مما يعني ضعفي وهي الصلة أو احتمالية التاثير، ويرجع ذلك لقصر الهن السلسلة واقتصار تصدير المحصول من الأراضي الجديدة وإستبعاد الأراضي القديمة لاحتمالية الأصابة بالعفن البني. كما يعتبر توافر الاصناف الصالحة للتصنيع أحدي نقاط القوة. وعلي الرغم من توضيح مزارعي العينة أن الأصناف المزروعة

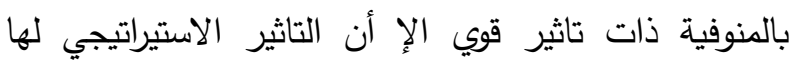
متدني لقربها من المحور السيني، ويرجع ذلك لمحدودية الأصناف المزروعة بالمنوفية. 


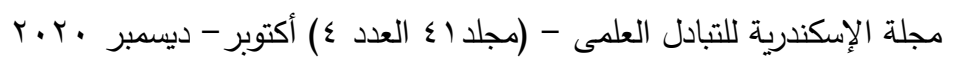

الجدول (Y M) حيث يمكن تطبيق إستراتيجية نمو وتوسع وذلك بالإستفادة من نقاط القوة والفرص المتاحة، وهي تعتبر أهم إستراتيجية للنهوض بالمنتج. تليها إستراتيجية التطوير والتحسين وذلك بالإستفادة من الفرص المتاحة ومواجهة نقاط الضعف بحل المشاكل للبيئة الداخلية للمنتج. أما إستراتيجية الثبات والاستقرار، وتهدف الي الاستغلال الأمثل للموارد وتقليل الهدر بمواجهة التهديدات وفق بعض الايجابيات المتاحة. وتأتي الإستراتيجية الأنكماشية في حالة تردي الأوضاع وذلك بزيادة مستويات الضعف والتهديدات، وتعتمد الإستريه هذه الإستراتيجية علي علاج مشكلة مستلزمات الإنتاج والمتمثلة في التقاوي.
يليها في التاثير كل من إمكانية إنشاء مراكز تجميع

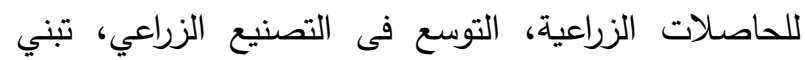
الدولة لإستباط أصناف محلية، إتجاه الدولة لتطوير نظم الري والصرف. وهذا ما تهدف وتسعي إليه الدولة من خلال

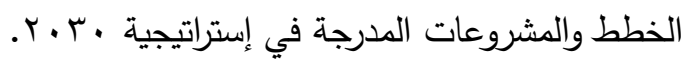
ء .تحديد أهم الإستراتيجيات المتبعة للنهوض بسلسلة إنتاج وتداول البطاطس. من واقع تحليل سلسلة القيمة لمحصول البطاطس وفق أراء مبحوثي العينة وهم الفئات الفعالة داخل سلسلة القيمة لمحصول البطاطس بالمنوفية، يمكن إتباع بعض الإستراتيجيات للنهوض بالمنتج ويتضح ذلك من خلال بله لبهن

جدول r I ـ مصفوفة استراتيجيات التحليل الرباعي لمحصول البطاطس SWOT مصفوفة

\begin{tabular}{|c|c|c|}
\hline مجالات الضعف (W) & مجالات القوة (S) & الخارجية الداخلية \\
\hline 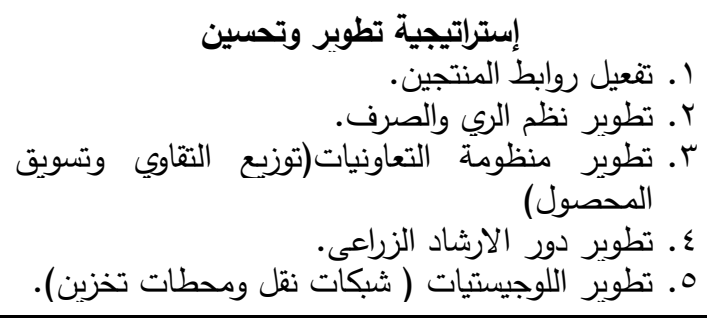 & 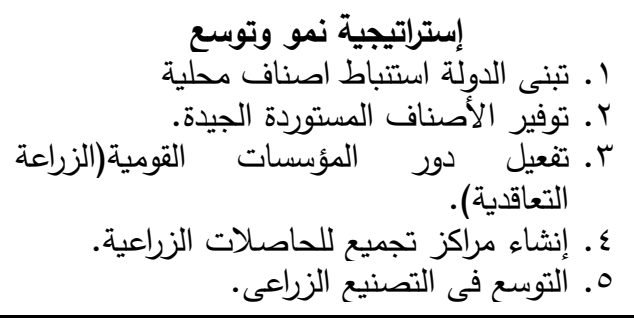 & الفرص (0) \\
\hline 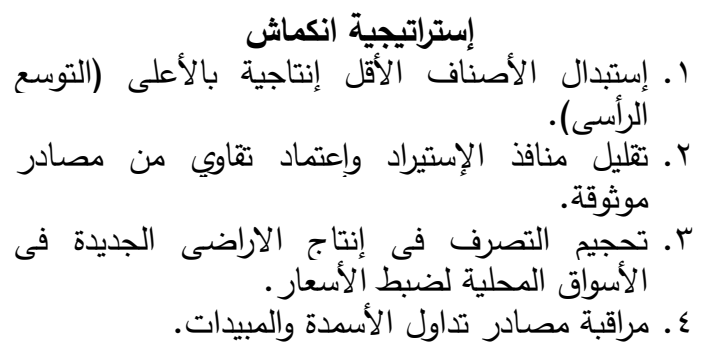 & 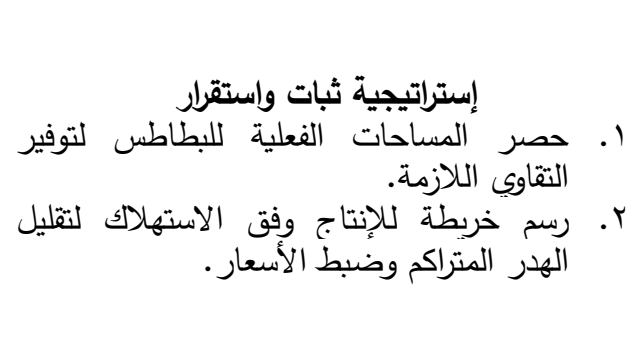 & التهديدات (T) \\
\hline
\end{tabular}




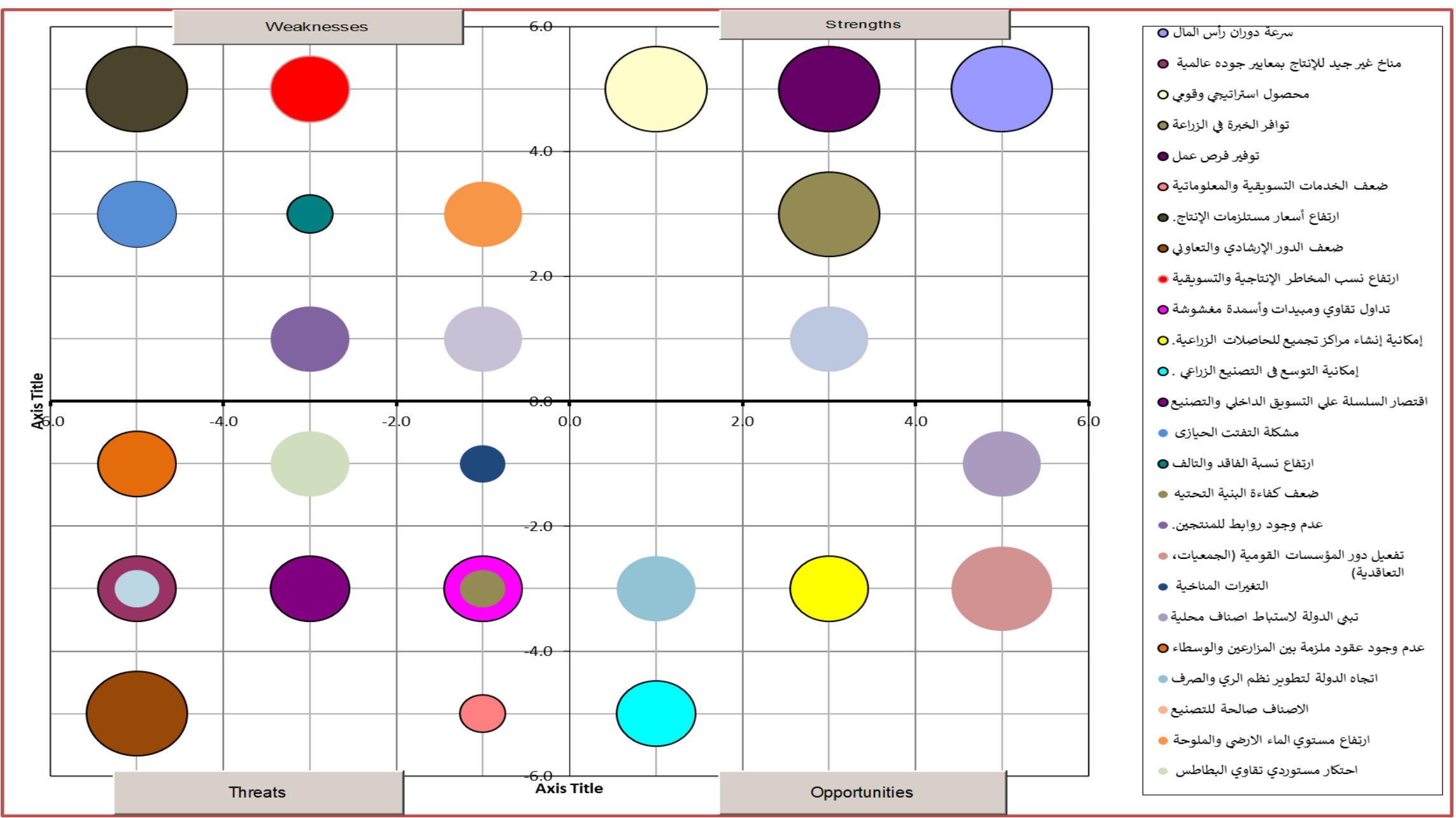

الثكل التخطيطي ץ. نموذج التحليل الرباعي للبطاطس وفق أراء الجهات الفعالة بالسلسلة 


\section{المراجح}

أحمد نصر الله، تحليل سلاسل القيمة للاستزراع السمكي والمصايد بجمهورية مصر العربية، المركز الدولي للأسماك، ماليزيا .$r \cdot I r$

الجهاز المركزي للتعبئة العامة والإحصاء، نشرات التجارة الجارجية، أعداد مختلفة.

سجلات مديرية الزراعة بمحافظة المنوفية ، إدارة الحيازة لعام

$$
\text { .r. r } / T \cdot r \text {. }
$$

وزارة التعاون الدولي وآخرون، تحليل سلاسل القيمة لمحصول اليانسون، برنامج التتمية الزراعية المستدامة وزيادة فرصل

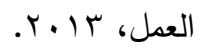

وزارة الزراعة، قطاع الشئون الإقتصادية، نشرات الإحصاءات

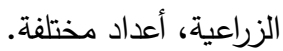

MarketWare International 2001-2004

Michael E. Porter ,Competitive advantage: Creating and sustaining superior performance, 1985.

Martin and others - Building competitiveness in Africa's Agriculture, A guide to Value chain concepts and Applications, World Bank, 2010.

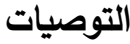

1. مراعاة الفجوات الإنتاجية بين المواسم الزراعية لضبط الأسعار المحلية وتقليل هدر الموارد الزراعية. r. تفعيل كل من إستراتيجية النمو والتوسع، وإستراتيجية التطوير والتحسين للنهوض بالمنتج.

r. تخطيط حجم الإنتاج لضبط الأسعار المحلية وتقليل واردات التقاوي، حيث يقدر الطلب المحلي بحوالي r. V.

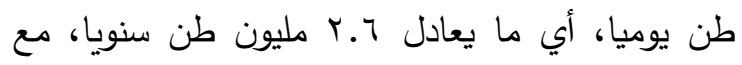
إضافة نسبة صادرات تقدر بنحو . ب٪. وهو ما يعني ضبط مستوي الإنتاج في حدود ه.ب : 0. مليون طن سنوياً. ء. توجيه إنتاج الاراضي الجديدة للسوق الخارجي واعتماد إنتاج الاراضي القديمة للسوق الداخلي للدحافظة علي

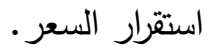


الملاحق

جدول ا. تطور مساحة وإنتاج البطاطس علي مستوي إجمالي العروات لجمهورية مصر العربية ومحافظة المنوفية خلال الفترة

\begin{tabular}{|c|c|c|c|c|c|c|}
\hline \multicolumn{3}{|c|}{ إجمالى العروات لمحافظة المنوفية } & \multicolumn{3}{|c|}{ إجمالى العروات للجمهوربـة } & \multirow{2}{*}{ البيان } \\
\hline (ألف طنالنا ج) & 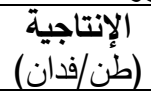 & 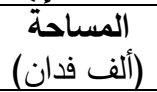 & (ألف طن الإنتاج) & 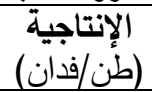 & 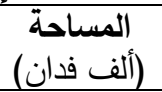 & \\
\hline$\leq \leqslant 9.9$ & 9.59 & $\varepsilon V . r$ & TV.乏 & $1 \cdot .04$ & $\mu . . v$ & $r \ldots o$ \\
\hline$r \leqslant \Lambda .0$ & 9.07 & r... & ג.rוז & 1.0. & $r Y . . r$ & $r \ldots r$ \\
\hline EIT.K & rו.. & $\varepsilon . V$ & YVT..0 & $1 . . V \varepsilon$ & rov.. & $r . . v$ \\
\hline$\varepsilon V \cdot .0$ & 1.00 & $\varepsilon \varepsilon . \wedge$ & rotv. & $1 . .19$ & TY.E & $r . \Lambda$ \\
\hline$\leqslant \leqslant \wedge .9$ & $1 . K V$ & $\varepsilon r . V$ & r & 11.1. & rrq.V & $r . . q$ \\
\hline (ז) & $1 . .0 r$ & $\varepsilon \varepsilon .1$ & rצז. & $1 . . \wedge 7$ & I. & $r .1$. \\
\hline$T$ T & $1 \ldots 0$ & TY.O & 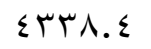 & 11.1 & ג.. & $r .11$ \\
\hline VIT.ร & $11 . V Y$ & $70 . \varepsilon$ & $\varepsilon \vee ० \wedge$. & $11.4 \wedge$ & EYI. .9 & $r+1 r$ \\
\hline$\varepsilon V T . \varepsilon$ & $1 . .79$ & $\varepsilon \varepsilon . \mu$ & $\varepsilon r 70 . r$ & 11.11 & ऍ人 . & $r \cdot 1 r$ \\
\hline I & $1 \ldots$ & $\varepsilon r . r$ & $\leq 711.1$ & 11.47 & $\varepsilon .9 .0$ & $r+1 \varepsilon$ \\
\hline ะ & $9.0 \leq$ & $\varepsilon q . r$ & $\leqslant 900 . \leqslant$ & سז.1 & $\varepsilon r V . \varepsilon$ & Y. 10 \\
\hline$r \varepsilon 1 . r$ & $V .9 r$ & $\varepsilon r .1$ & $\varepsilon \|$ I & $1 . .9 r$ & rV7.7 & $r .17$ \\
\hline$\varepsilon \vee \leq .7$ & 9.19 & $\varepsilon \wedge$. & $\varepsilon \wedge \leqslant 1 .$. & $11.7 \mathrm{~V}$ & $\varepsilon \mid \leqslant .9$ & $r .1 \mathrm{~V}$ \\
\hline or... & 11.99 & $\leqslant 7.9$ & $\varepsilon 97 . .1$ & 14.10 & $\varepsilon \cdot \wedge .1$ & $r \cdot 1 \Lambda$ \\
\hline$\varepsilon \leqslant 9 . r$ & 11.11 & $\varepsilon \cdot . \varepsilon$ & Or...r & |Y.M & EYY.T & $r .19$ \\
\hline$\varepsilon 79.1$ & $1 . r$ & $\varepsilon 7$. & $\varepsilon . \vee 7 . r$ & $11 . r$ & rYY.r & المتوسط \\
\hline
\end{tabular}

المصدر : جمعت وحسبت من وزارة الزراعة واستصلاح الأراضي، قطاع الثئون الاقتصادية،أعداد متفرقة.

جدول r. ن نتائج تحليل التباين لمتوسط الاحتياجات الفدانية من مستلزمات الإنتاج بمحافظة المنوفية للموسم الزراعي

$(r \cdot r / / r \cdot r \cdot)$

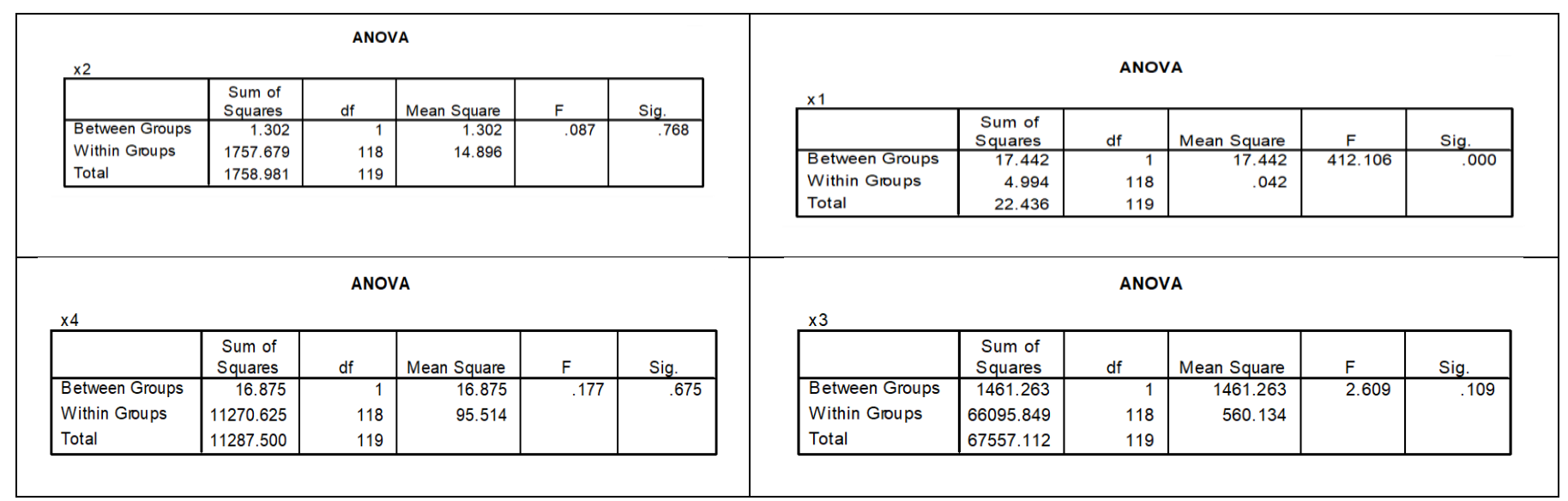




\begin{tabular}{|c|c|c|c|c|c|c|c|c|c|c|c|}
\hline \multicolumn{6}{|c|}{ ANOVA } & \multicolumn{6}{|c|}{ ANOVA } \\
\hline & $\begin{array}{l}\text { Sum of } \\
\text { Squares }\end{array}$ & df & Mean Square & $\mathrm{F}$ & Sig. & & $\begin{array}{l}\text { Sum of } \\
\text { Squares }\end{array}$ & df & Mean Square & \multirow{4}{*}{$\frac{F}{1.422}$} & Sig. \\
\hline Between Groups & 2233.876 & 1 & 2233.876 & \multirow[t]{3}{*}{2.605} & \multirow[t]{3}{*}{.109} & Between Groups & 172.800 & 1 & 172.800 & & \multirow[t]{3}{*}{.236} \\
\hline Within Groups & 101185.4 & 118 & \multirow[t]{2}{*}{857.504} & & & Within Groups & 14342.400 & 118 & \multirow[t]{2}{*}{121.546} & & \\
\hline Total & 103419.3 & 119 & & & & Total & 14515.200 & 119 & & & \\
\hline \multicolumn{6}{|c|}{ ANOVA } & \multirow{2}{*}{\multicolumn{6}{|c|}{ ANOVA }} \\
\hline \multicolumn{6}{|l|}{ s8 } & & & & & & \\
\hline & $\begin{array}{r}\text { Sum of } \\
\text { Squares }\end{array}$ & df & Mean Square & $\mathrm{F}$ & \multirow{4}{*}{$\frac{\text { Sig. }}{.000}$} & & $\begin{array}{l}\text { Sum of } \\
\text { Squares }\end{array}$ & $d f$ & Mean Square & $\mathrm{F}$ & \\
\hline Between Groups & 13.804 & 1 & 13.804 & \multirow[t]{3}{*}{13.351} & & Between Groups & $\frac{\text { Squares }}{8.533}$ & ai 1 & $\begin{array}{r}\text { IVean square } \\
8.533\end{array}$ & F & $\frac{\text { Sig. }}{.532}$ \\
\hline Within Groups & 122.002 & 118 & & & & Within Groups & 2557.433 & 118 & 21.673 & & \\
\hline Total & 135.806 & 119 & & & & Total & 2565.967 & 119 & & & \\
\hline
\end{tabular}

المصدر: جمعت وحسبت من بيانات العينة الميدانية.

\section{جدول r. نتائج تحليل التباين لمتوسط الاحتياجات الفدانية من العمل البشري والآلي بمحافظة المنوفية للموسم الزراعي}

$(r \cdot r)-r \cdot r \cdot)$

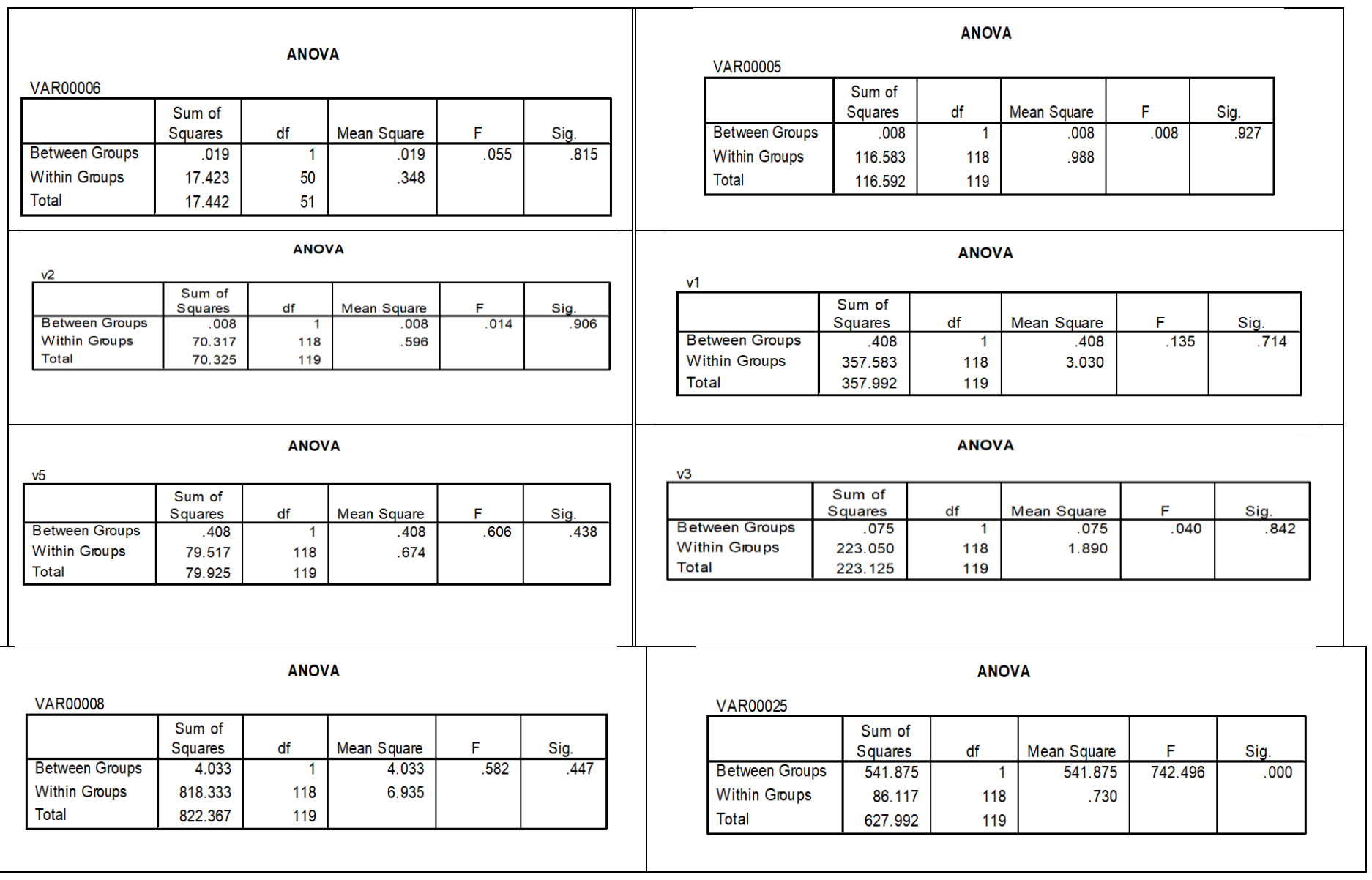


أمل كامل عيد رمضان و رانيا عبدالله السعيد طلبة: دراسة تحليلية لسلسلة القيمة لمحصول البطاطس بمحافظة المنوفية 657

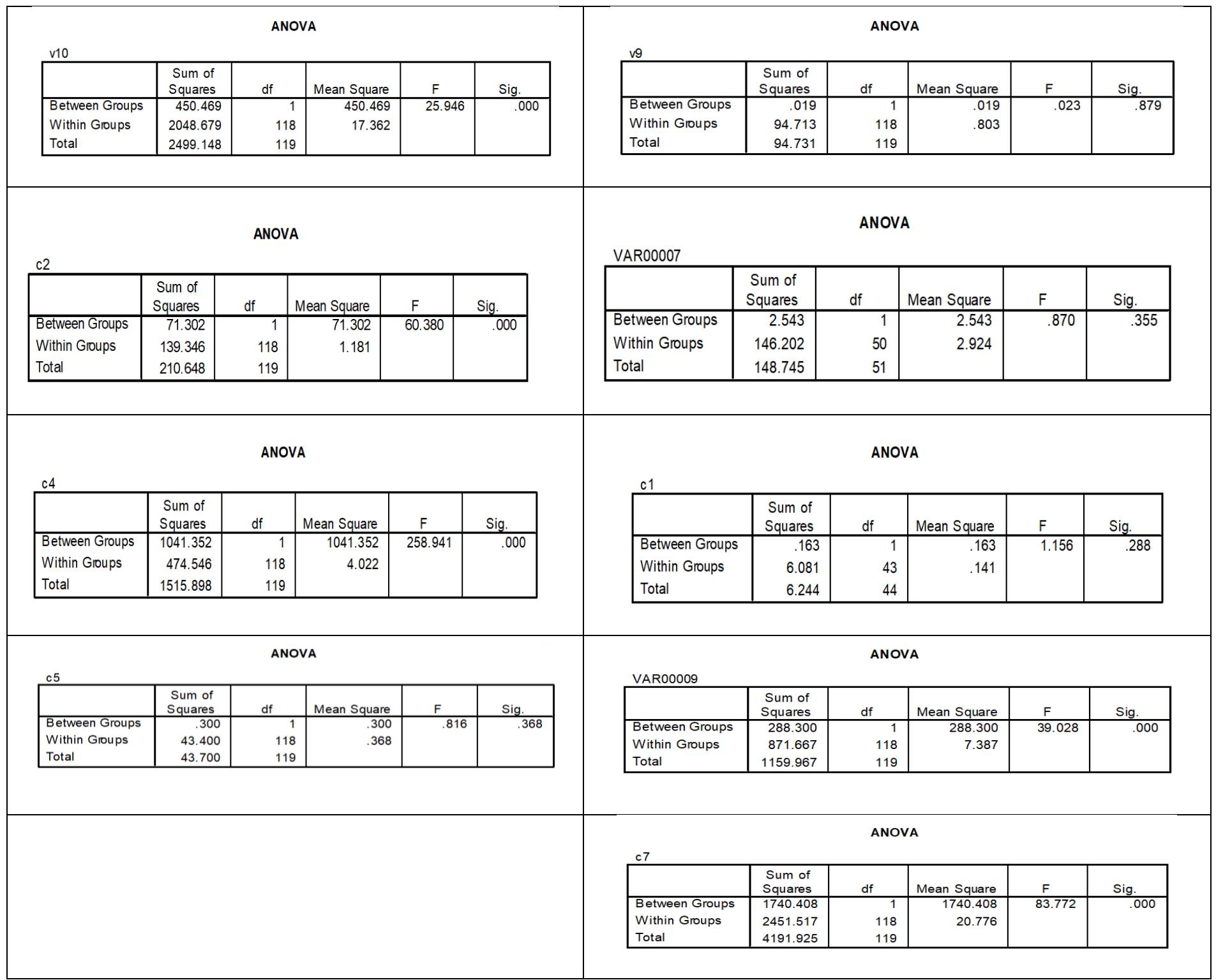

المصدر: جمعت وحسبت من بيانات العينة الميدانية. 


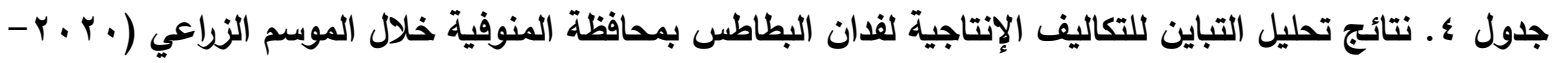

$(r \cdot r)$

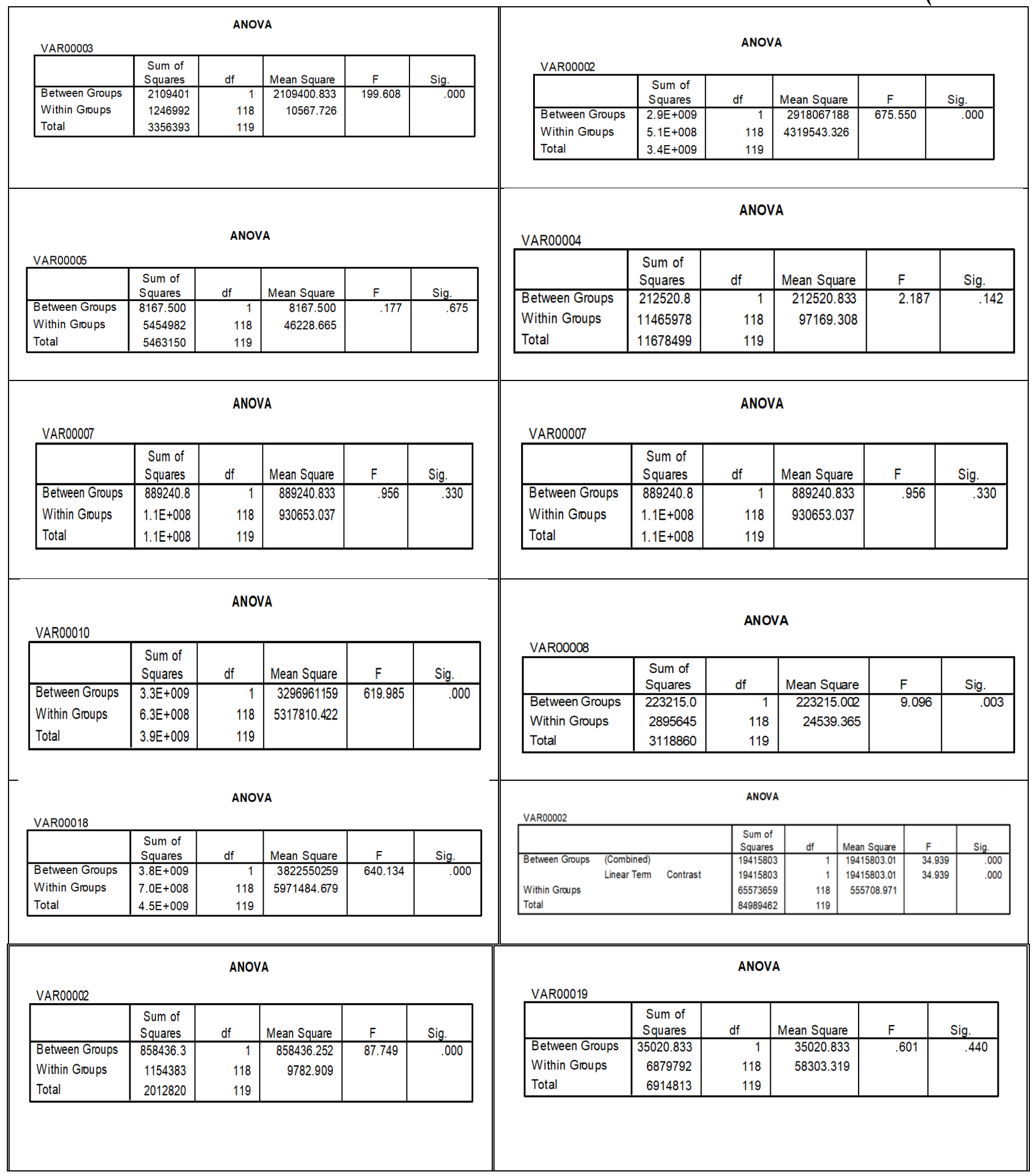


أمل كامل عيد رمضان و رانيا عبدالله السعيد طلبة: دراسة تحليلية لسلسلة القيمة لمحصول البطاطس بمحافظة المنوفية 659

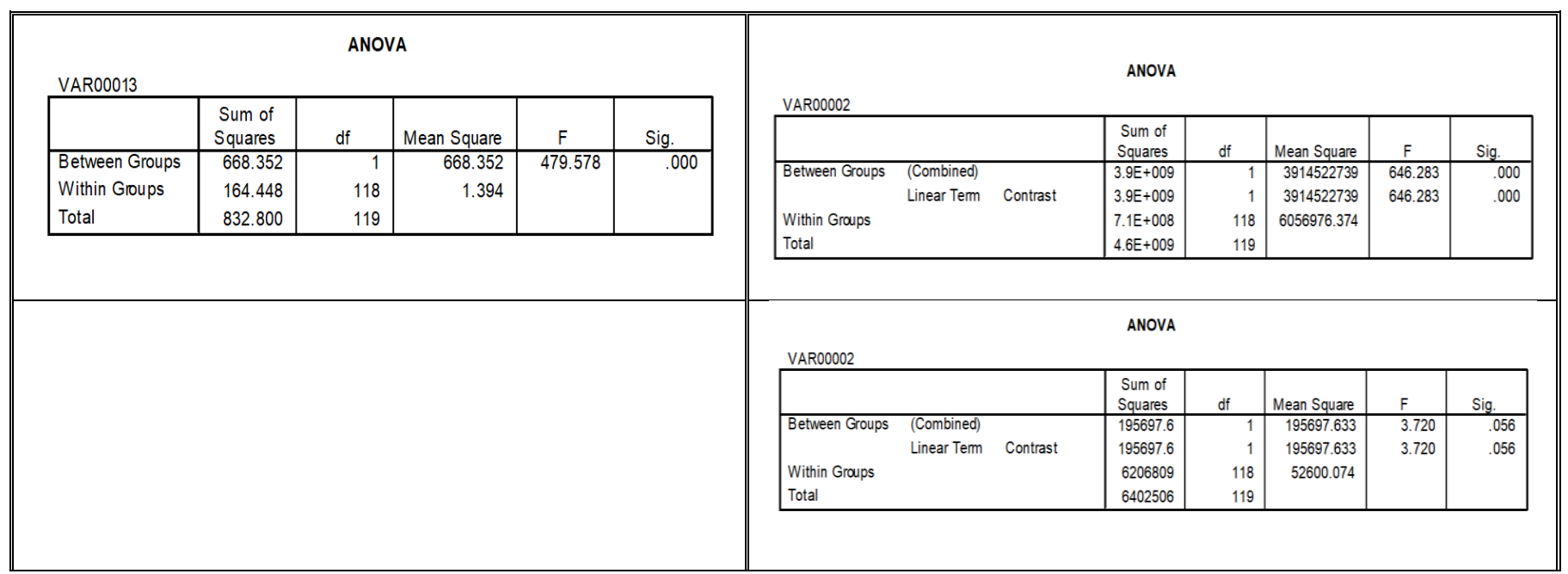

المصدر: جمعت وحسبت من بيانات العينة الميدانية. 


\title{
ABSTRACT Analytical Study of Potato Value Chain in Menoufia Governorate
}

\author{
Amal Kamel Eid Ramadan and Rania Abdallah El Saied Tolba
}

By analyzing the production outputs of potato per feddans in Menoufia Governorate, it is found that the loss between 5\%: $10 \%$. The value of family consumption and gifts is estimated at $2 \%$. Accordingly, the quantity sold per feddan during the two agricultural seasons is estimated about 14.7 and 11.3 tons / feddan. By analyzing the marketing chain of the crop, it is evident that there are 3 effective parties to deal with, and it has also been found that there are no systems in place to connect farmers to markets. Reviewing the value chain, it becomes clear that the chain is divided into a group of production and service processes, as it begins with pre-production processes, which are represented in providing production requirements for the crop. The groups responsible for this stage are seed suppliers, distributors of fertilizers and pesticides, and agricultural associations. Pre-production operations follow the production process and the main actor in it is the farmer. The sample farmers explained that the final production is distributed between the sorting and storage stations and is dealt with in the case of storage to take advantage of the price difference at the end of the summer season, or storage as seed for the winter season represents $10 \%$ of the production. As for suppliers (intermediaries), their role is limited to contracting with the farmer on the price, whether before planting or before harvest, and selling to factories or central markets.

While some farmers deal with factories directly as a result of contracting some varieties such as Hormuz, Santana, Cruz. The managers of the studied factories explained that about $10 \%$ of processed potatoes come from Menoufia Governorate, and the percentage of processed potatoes in the local market is about $50 \%$ : $60 \%$, while exports of the product represent about $40 \%$ : $50 \%$ and exports are concentrated in African markets and some Arabic countries. The farmers explained that they are dealing with wholesalers for providing seeds and fertilizers on credit. The wholesalers also indicated that in the case of purchasing from the central market, it is preferable to buy in practice, for a commission of $7 \%$ for the auction system. On the other hand, the absence of a link between the retailer and the farmer directly, as about $90 \%$ of the sample farmers explained the difficulty of selling potatoes to retailers directly, due to the large volume of production.

By studying the added value of potatoes, it was found that it provides job opportunities throughout the production and marketing chain of the summer and winter potato crop, estimated about 4.95, 5.85 workers / ton, which is attributed to pay attention to this crop due to its high employment rates. By studying the added monetary value of the produced, it becomes clear that the profits of the intermediaries exceed the profits of the producers, and accordingly, activating the role of contract farming contributes to raising the level of farmers' income and ensuring fair profitability for the farmer, according to binding contracts for all parties.

By conducting a SOWT analysis of the value chain of potatoes in Menoufia Governorate, it becomes clear that the strengths are the rapid turnover of capital, the availability of expertise in agriculture and the creation of job opportunities, and that the potato crop is a strategic and national crop. Whereas, the weaknesses are the high prices of production inputs, the high rates of production and marketing risks, the problem of housing fragmentation, the absence of links to producers, and the high rates of waste and spoilage.

Threats come as one of the external factors affecting the product and are represented by the weak extension and cooperative role, the increase in the number of middlemen, the weak infrastructure efficiency, the circulation of adulterated seeds, pesticides and fertilizers, the absence of binding contracts between farmers and intermediaries, the monopoly of importers of potato seeds. The available opportunities are considered the most important supporter of the crop, so the activation of the role of national institutions represented in cooperative societies and contractual crops is considered the most important variables affecting the yield, followed by the effect of each of the possibility of establishing collection centers for agricultural crops, expansion in agricultural industrialization, the state's adoption of the introduction of local varieties, the state's direction to develop systems Irrigation and drainage. This is what the state aims through the plans and projects included in the 2030 Strategy.

Based on the analysis of the value chain of the potato crop according to the opinions of the sample respondents, the most important strategies used to promote the potato production and circulation chain in Menoufia Governorate were identified. The most important of which is the implementation of a growth and expansion strategy, followed by the development and improvement strategy. As for the stability and stability strategy, which aims to optimize the utilization of resources and reduce waste by confronting threats, 
according to some of the advantages available. The deflationary strategy comes in the event of a deteriorating situation by increasing levels of vulnerability and threats. This strategy depends on treating the problem of production requirements, which is primarily the problem of seeds.

\section{Recommendations:}

1. Correct handling of production gaps between agricultural seasons to control local prices and reduce the waste of agricultural resources.

2. Activating both the growth and expansion strategy, and the development and improvement strategy to promote the product.
3. Planning the volume of production to control domestic prices and reduce seed imports, as the local demand is estimated at about 2.6 million tons annually .This means adjusting the level of production in the range of 3.5: 4.5 million tons annually.

4. Directing the production of new lands to the external market and approving the production of old lands for the internal market to maintain price stability.

Key words: value chain - SWOT model stakeholders - analysis of variance. 